\title{
Metabolic engineering of Clostridium beijerinckii to improve glycerol metabolism and furfural tolerance
}

\author{
Chidozie Victor Agu ${ }^{1,2}$, Victor Ujor ${ }^{3}$ and Thaddeus Chukwuemeka Ezeji ${ }^{*^{*}}$ (])
}

\begin{abstract}
Background: Inefficient utilization of glycerol by Clostridium beijerinckii (Cb) is a major impediment to adopting glycerol metabolism as a strategy for increasing $\mathrm{NAD}(\mathrm{P}) \mathrm{H}$ regeneration, which would in turn, alleviate the toxicity of lignocellulose-derived microbial inhibitory compounds (LDMICs, e.g., furfural), and improve the fermentation of lignocellulosic biomass hydrolysates $(\mathrm{LBH})$ to butanol. To address this problem, we employed a metabolic engineering strategy to enhance glycerol utilization by $C b$.

Results: By overexpressing two glycerol dehydrogenase (Gldh) genes (dhaD1 and gldA1) from the glycerol hyperutilizing Clostridium pasteurianum $(C p)$ as a fused protein in $C b$, we achieved approximately $43 \%$ increase in glycerol consumption, when compared to the plasmid control. Further, Cb_dhaD 1 + gldA1 achieved a 59\% increase in growth, while butanol and acetone-butanol-ethanol (ABE) concentrations and productivities increased $14.0 \%, 17.3 \%$, and $55.6 \%$, respectively, relative to the control. Co-expression of $d h a D 1+g / d A 1$ and $g / d A 1+$ dihydroxyacetone kinase (dhaK) resulted in significant payoffs in cell growth and ABE production compared to expression of one Gldh. In the presence of 4-6 g/L furfural, increased glycerol consumption by the dhaD $1+\mathrm{g} / \mathrm{dA} 1$ strain increased cell growth (> 50\%), the rate of furfural detoxification (up to 68\%), and ABE production (up to 40\%), relative to the plasmid control. Likewise, over-expression of $[(\mathrm{dhaD} 1+$ gldA1) $\mathrm{dhaK}]$ improved butanol and ABE production by $70 \%$ and $50 \%$, respectively, in the presence of 5 and $6 \mathrm{~g} / \mathrm{L}$ furfural relative to the plasmid control.

Conclusions: Overexpression of $C p$ gldhs and dhaK in Cb significantly enhanced glycerol utilization, ABE production, and furfural tolerance by $\mathrm{Cb}$. Future research will address the inability of recombinant $\mathrm{Cb}$ to metabolize glycerol as a sole substrate.
\end{abstract}

Keywords: Metabolic engineering, Butanol, Glycerol, Furfural, C. beijerinckii, C. pasteurianum, Glycerol dehydrogenase, Dihydroxyacetone kinase

\section{Background}

Due to the finite nature of crude oil, coupled with environmental concerns associated with the consumption of fossil fuels, biofuels have gained significant attention over the past few decades. For instance, biodiesel production in the US has increased substantially from 75 million gallons per annum in 2005 to approximately 2 billion

\footnotetext{
*Correspondence: ezeji.1@osu.edu

${ }^{1}$ Department of Animal Sciences and Ohio State Agricultural Research and Development Center (OARDC), The Ohio State University, 305

Gerlaugh Hall, 1680 Madison Avenue, Wooster, OH 44691, USA

Full list of author information is available at the end of the article
}

gallons in $2017[1,2]$. Notably, $\sim 10 \%$ of the oil feedstock used for biodiesel production ends up as crude glycerol. Consequently, in 2017, an estimated 200 million gallons of crude glycerol was available as a potential fermentation feedstock. Consequently, crude glycerol is a financial and environmental liability due to the attendant cost of disposal [3]. Crude glycerol must be refined to a higher purity to remove contaminants such as alcohol and salts before it can be applied in industrial chemical processes [3]. However, the purification process, which costs $\sim \$ 0.2 /$ $\mathrm{lb}$, excluding the cost of transportation to the glycerol refinery increases the retail price of glycerol from $\$ 0.05 /$ 
$\mathrm{lb}$ to about $\$ 0.60-\$ 0.90 / \mathrm{lb}$, representing a $300 \%$ increase [3]. More importantly, glycerol biorefineries and glycerol markets are currently overwhelmed by excess supply of crude and refined glycerol, respectively.

In light of the need to manage this glycerol glut, it is imperative to develop microbial systems for bioconversion of glycerol into value-added products. Fermentation of glycerol by microbes such as Clostridium, Klebsiella, Citrobacter, and Enterobacter species has emerged as a desirable channel for disposing of excess crude glycerol. The use of solventogenic Clostridium species for glycerol fermentation is attractive, largely because of the costeffective nature of microbial fermentation $[4,5]$. Thus, glycerol has emerged as an alternative non-food fermentation substrate for microbial production of biofuels and other microbe-derived chemicals. Moreover, glycerol catabolism generates two additional moles of reducing equivalents relative to the consumption of molar equivalent of glucose [6-9]. The resulting reducing power from glycerol catabolism has been shown to facilitate detoxification of lignocellulose-derived microbial inhibitory compounds (LDMICs). Another non-food substrate, lignocellulosic biomass (LB) - such as corn stover, switchgrass, Miscanthus, sawdust, and wood shavings-is presently abundant. However, due to the recalcitrance of LB to depolymerization, LB feedstocks must first be pretreated to ensure efficient release of fermentable sugars by saccharolytic enzymes during hydrolysis $[10,11]$. Notably, LB pretreatment generates LDMICs, especially furaldehydes (e.g., furfural) and phenolic compounds that limit the fermentation of lignocelluloses-derived sugars to fuels and chemicals [12].

In light of these two challenges-glycerol glut and LDMIC-mediated toxicity-we explored metabolic engineering as a tool for channeling the excess reducing equivalents from glycerol catabolism towards in situ furfural detoxification during fermentation by $C b$ [13]. Previously, we had identified increased $\mathrm{NAD}(\mathrm{P}) \mathrm{H}$ regeneration as the underpinning for improvements in the fermentation profile (increased growth and solvent production) of glycerol-supplemented, furfural-challenged $\mathrm{Cb}$ cultures (although glycerol utilization by $C b$ was considerably low, when compared to glucose consumption) [13]. Increasing glycerol utilization by $C b$, therefore, represents a rational approach, not only for increasing furfural detoxification (bioabatement) and butanol production by coupling excess $\mathrm{NAD}(\mathrm{P}) \mathrm{H}$ resulting from glycerol catabolism to furfural reduction and butanol biosynthesis, but also as a cost-effective solution to glycerol glut. Different authors have demonstrated that glycerol has to be supplied at a high concentration; 1:2 molar ratio of glucose to glycerol (36 g/L glucose: $36.1 \mathrm{~g} / \mathrm{L}$ glycerol), to minimize glucose-mediated repression of glycerol utilization (carbon catabolite repression) [13-15]. Consequently, large amounts of glycerol are left unutilized post fermentation, which currently constitutes a major economic and technical drawback to this approach. A previous attempt to adapt $\mathrm{Cb}$ to glycerol as a sole carbon source was not successful [16]. In fact, no $\mathrm{Cb}$ strain capable of growth on glycerol as a sole source of carbon was isolated following prolonged incubation or repeated transfer to fresh glycerol-containing medium [16].

We, therefore, hypothesized that wild-type $C b$ harbors significant metabolic roadblocks to glycerol catabolism, which could be circumvented by metabolic rewiring of the glycerol catabolic machinery of $C b$ via metabolic engineering. Towards this goal, we identified Clostridium pasteurianum $(C p)$, an efficient hyper-glycerol-utilizing bacterium [17-19] as a donor of efficient glycerol catabolic repertoire. However, a number of salient factors justify retaining $\mathrm{Cb}$ as the model butanol-producing cell factory. First, although $C p$ can utilize glycerol as a mono-substrate to produce butanol and 1,3-propanediol, it does not efficiently transition to solventogenesis during fermentation of mixed sugar substrates, as evidenced by butyric acid accumulation as the major fermentation product [17-19], hence, limiting the use of $C p$ to ferment LB hydrolysates to butanol. Second, unlike $C p$, the tolerance of $C b$ to LDMIC has been extensively studied [10, $20-22]$. Lastly, $C b$ tolerates butanol toxicity better than $C p[16,18,23]$.

Glycerol catabolism to butanol by solventogenic Clostridium species proceeds via an initial two-step reaction that feeds the resulting intermediates directly into the glycolytic pathway. First, $\mathrm{NAD}^{+}$-dependent glycerol dehydrogenase (Gldh) catalyzes the oxidation of glycerol to dihydroxyacetone (DHA). Next, dihydroxyacetone kinase (DhaK) catalyzes the phosphorylation of DHA to dihydroxyacetone phosphate (DHAP), a glycolytic intermediate (Fig. 1). In this study, we focused on Gldh overexpression in $C b$, not only because it catalyzes an $\mathrm{NAD}(\mathrm{P}) \mathrm{H}$-generating reaction, but also because of the multiplicity Gldh in $C p$. While $C b$ has only one glycerol dehydrogenase gene, $C p$ has four copies (dhaD1, dhaD2, gldA1, and gldA2), that vary significantly in terms of protein sequence and secondary structure. Both microorganisms have a single copy of dhaK. Therefore, we sought to systematically overexpress these glycerol catabolic genes from $C p$ in $C b$, thereby constructing $\mathrm{Cb}$ strains that can efficiently co-metabolize glycerol and lignocellulosic sugars to butanol. Preliminary studies did not reveal marked differences in glycerol utilization and solvent production by different recombinant $\mathrm{Cb}$ strains expressing the different $g l d h s$ from $C p$. Therefore, in the current study, dhaD1, gldA1 and dhaK from $C p$ were cloned in $C b$. DhaD2 and GldA2 will be targeted in 


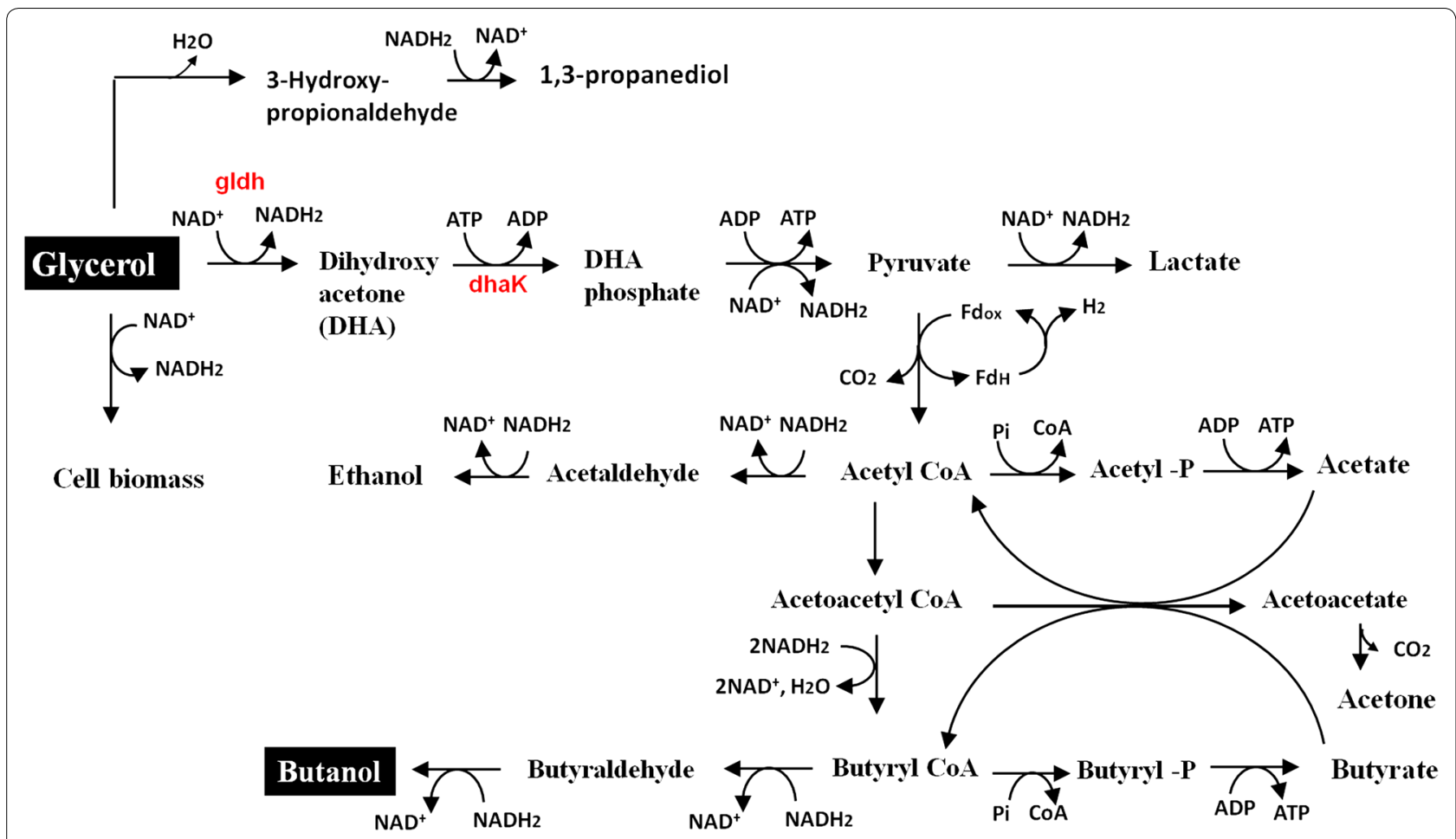

Fig. 1 Schematic representation of combined pathways for glycerol utilization in C. beijerinckii and C. pasteurianum. The pathway is abridgedadditional steps between Acetoacetyl CoA and Butryl CoA are not included

future studies. To the best of our knowledge, this is the first attempt at metabolic engineering of $C b$ specifically for enhanced glycerol utilization, as a means of increasing tolerance to LDMICs such as furfural.

\section{Results}

Protein sequence analyses and secondary structure alignments of $C p$ and $C b$ Gldh and DhaK

Whole genome analysis revealed four copies of gldh in $C p$ and one $d h a K$. Conversely, $C b$ has a single copy of each gene. NCBI Blast $p$ analysis revealed considerable sequence differences among all four Cp Gldhs, and between $C p$ Gldhs and the single $C b$ Gldh (Additional file 1: Table S1). Similarly, the DhaKs from $C p$ and $C b$ vary significantly in terms of their protein sequences (Additional file 1: Table S3). Alignments of the secondary structures of these proteins revealed significant structural disparities among them, as indicated by the resulting high root mean square deviations (RMSD; Additional file 1: Table S2). Because the alignment of the glycerol dehydrogenases, DhaD1 and GldA1 from $C p$, produced the least RMSD value, which implies closely matched secondary structures, the genes encoding these two enzymes were, therefore, targeted for initial overexpression as fused proteins with the DhaK gene (from $C p$ ) in $C b$.
Overexpression of $C p$ GldA 1 and DhaD1 as single proteins in $C b$ improved growth with marginal increases in solvent production

To generate recombinant $\mathrm{Cb}$ strains that can efficiently utilize glycerol as a carbon source, genes that encode Gldhs and DhaK in the hyper-glycerol-utilizing $C p$ were systematically overexpressed in $C b$. Two of the four genes that encode Gldhs (gldA1 and dhaD1) in $C p$ were first overexpressed as single proteins in $C b$ under the control of an inducible acetoacetate decarboxylase- $a d c$ (pWUR459) or a constitutive thiolase (pWUR460) promoter to generate four recombinant $\mathrm{Cb}$ strains: $C b$ pWUR459_gld $A 1, C b$ pWUR460_gld $A 1, C b$ pWUR459_dhaD1, and $C b$ pWUR460_dhaD1. The empty plasmid control ( $\mathrm{Cb}$ pMTL500E) consisted of the backbone plasmid without insert and promoter.

The fermentation profiles of $C b$ pWUR460 gld $A 1$ and $C b$ pWUR460_dhaD1 (constitutively expressing Gldhs) are shown in Fig. 2, while those of $C b$ pWUR459_gldA1 and $C b$ pWUR459_dhaD1 (inducible expression of Gldhs) are shown in Fig. 3. With both constitutive and inducible overexpression, we observed similar fermentation profiles in terms of cell growth and solvent production between strains overexpressing gldA1 and dhaD1, indicating similar catalytic activity for both enzymes towards glycerol. Expectedly, the fermentation profiles 

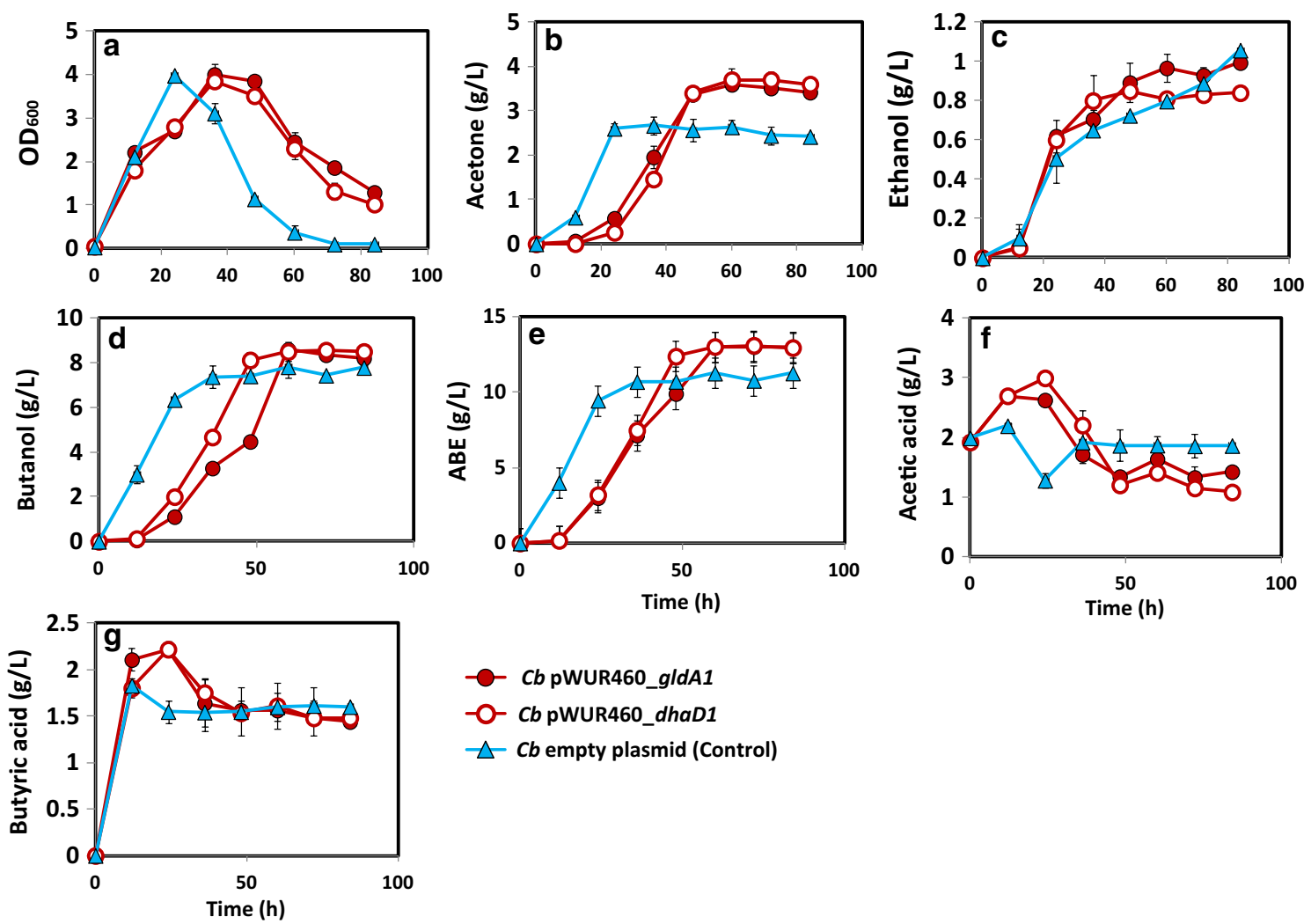

$\triangle C$ b empty plasmid (Control)

Fig. 2 The Fermentation profiles of constitutive Cb pWUR460_dhaD1 and Cb pWUR460_gldA1 during growth in glycerol-supplemented glucose medium. a Cell growth in terms of $\mathrm{OD}_{600}, \mathbf{b}$ acetone, $\mathbf{c}$ ethanol, $\mathbf{d}$ butanol, $\mathbf{e} \mathrm{ABE}, \mathbf{f}$ acetic acid, $\mathbf{g}$ butyric acid

of recombinant $C b$ strains $-C b \_g l d A 1$ and $C b \_d h a D 1-$ showed improved growth and solvent accumulation, relative to the plasmid control. Specifically, when expressed under the control of the constitutive promoter, gldA1 and dhaD1 showed marginal increases in cell growth relative to the plasmid control (Fig. 2a). Conversely, overexpression of $g l d A 1$ and $d h a D 1$ under the control of an inducible promoter increased cell growth $\sim 45 \%$ when compared to the plasmid control (Fig. 3a).

Butanol and total ABE production by the inducible $C b$ strains, $C b$ pWUR459_gldA1 and $C b$ pWUR459_dhaD1 were $8.75 \mathrm{~g} / \mathrm{L}$ and $12.7 \mathrm{~g} / \mathrm{L}$, and 8.5 and $12.97 \mathrm{~g} / \mathrm{L}$, respectively (Fig. 3d, e). These values were comparable to the constitutive strains- $C b$ pWUR460_gldA1 produced $8.6 \mathrm{~g} / \mathrm{L}$ and $13 \mathrm{~g} / \mathrm{L}$ butanol and ABE, respectively; while, $C b$ pWUR460_dhaD1 produced $8.56 \mathrm{~g} / \mathrm{L}$ and $13.01 \mathrm{~g} / \mathrm{L}$, respectively (Fig. 2d, e). Overall, butanol and total $\mathrm{ABE}$ concentrations were $>15 \%$ higher in the recombinant $\mathrm{Cb}$ strains, $C b \_g l d A 1$ and $C b \_d h a D 1$ relative to the plasmid control. The ABE productivities of $C b$ pWUR460_gldA1 and $C b$ pWUR460_dhaD1 were similar; $0.22 \mathrm{~g} / \mathrm{L} / \mathrm{h}$, which was $17 \%$ higher than that of the empty plasmid control $(0.18 \mathrm{~g} / \mathrm{L} / \mathrm{h})$. Interestingly, despite significant increases in cell growth by the induced gldA1- (Cb pWUR459_gldA1) and dhaD1-expressing ( $C b$ pWUR459_dhaD1) strains relative to the strains bearing constitutively expressed gldA1 and $d h a D 1$ and the plasmid control, these increases did not translate into increased total ABE production (Figs. 2a, 3a).

In regards to acid production and re-assimilation, constitutively expressed gldA1 and dhaD 1 accumulated higher acetic and butyric acid levels at $12 \mathrm{~h}$ and $24 \mathrm{~h}$ of fermentation, when compared to the plasmid control. Both strains, however, re-assimilated $>51 \%$ of the total acetic and butyric acids produced relative to $14.6 \%$ acetic acid and $12.02 \%$ butyric acid re-assimilation by the plasmid control (Fig. 2f, g). The induced gldA1 and dhaD1 showed similar acid production and re-assimilation patterns as the constitutive strains (Fig. 3f, g).

\section{Overexpression of $C p$ GldA1 (or DhaD1) with DhaK led to greater payoffs compared to overexpression of a single gldh}

By linking two enzymes of the same metabolic pathway, Dueber et al. [24] observed improvements in the local concentration of enzyme activity, with concomitant increase in the conversion rates of metabolic 

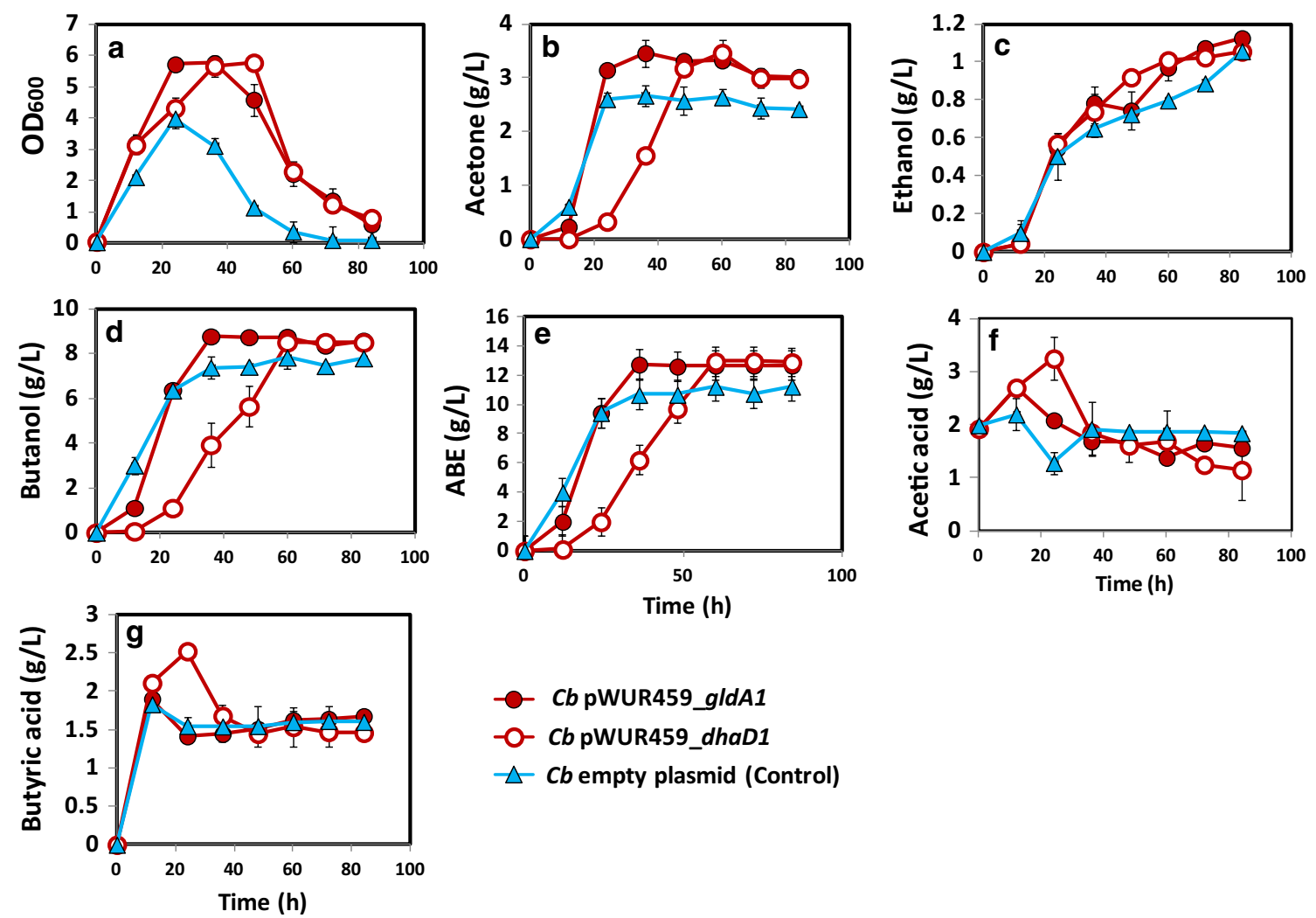

$\triangle C$ Cb empty plasmid (Control)

Fig. 3 Fermentation profiles of inducible Cb pWUR459_dhaD1 and Cb pWUR459_gldA1 during growth in glucose + glycerol medium. a Cell growth in terms of $\mathrm{OD}_{600}, \mathbf{b}$ acetone, $\mathbf{c}$ ethanol, $\mathbf{d}$ butanol, e $\mathrm{ABE}$, $\mathbf{f}$ acetic acid, $\mathbf{g}$ butyric acid

intermediates. This was the basis for fusing glycerol catabolic enzymes from $C p$ in $C b$, such that active sites exist in close proximity, whereby the product of one reaction is potentially utilized rapidly by the adjacent enzyme (Additional file 1: Figure S2). To ensure maximum payoff in terms of butanol production, $C p$ dhaK was covalently linked with each of $g l d A 1$ and $d h a D 1$, thereby expressing them as fused proteins. Because overexpression of gldA1 and dhaD1 as single proteins offered similar benefits, $\mathrm{Cb}$ was transformed with only the recombinant plasmids carrying gldA $1+$ dhaK to generate $C b$ pWUR459 $[g l d A 1+$ dhaK] and $C b$ pWUR460_[gldA1+dhaK]. The two strains were used to conduct batch $A B E$ fermentations in glucose + glycerol medium (1:2 molar ratio, respectively) supplemented with $20 \mu \mathrm{g} / \mathrm{mL}$ erythromycin.

Figure 4 compares the fermentation profiles of $C b$ pWUR459_[gldA1+dhaK] and $C b$ pWUR460_ $[$ gldA $1+$ dhaK $]$ to those of the plasmid control. Cell growth increased significantly $(40 \%)$ in the cultures of $C b$ pWUR460_[gldA1+dhaK] and $C b$ pWUR459_ [gldA1+dhaK], relative to the plasmid control. Similarly, butanol and ABE production increased $11.7 \%$ and $17 \%$, respectively, with $C b$ pWUR460_[gldA1+dhaK] and $13 \%$ and $14 \%$, respectively, with $C b$ pWUR459 [gldA1+dhaK], relative to the plasmid control. Also, the ABE productivity of $C b$ pWUR460_[gldA $1+d h a K]$ and pWUR459_[gldA1+dhaK] $(0.22 \mathrm{~g} / \mathrm{L} / \mathrm{h}$ and $0.36 \mathrm{~g} / \mathrm{L} / \mathrm{h}$, respectively) increased $22.2 \%$ and $50 \%$ relative to the plasmid control $(0.18 \mathrm{~g} / \mathrm{L} / \mathrm{h}$; Table 1$)$. Although, cell growth and $A B E$ productivity increased $21.8 \%$ and $11.4 \%$, respectively, with inducible expression ( $C b$ pWUR459 $[$ gldA $1+$ dhaK $])$, when compared to constitutive expression ( $C b$ pWUR460_[gldA1 + dhaK]; Fig. 4; Table 1), final butanol and $\mathrm{ABE}$ concentrations were similar for both strains. This result is consistent with the observation for constitutive versus inducible overexpression of GldA1 or DhaD1 as single proteins, indicating that inducible overexpression of these proteins results in accumulation of higher cell biomass, albeit with no significant payoffs in solvent accumulation.

Constitutive overexpression of gldA1 with dhaK as a fused protein resulted in significant increase in cell growth (35.8\%) when compared to constitutive overexpression of $g l d A 1$ alone. Nevertheless, the difference in butanol production was not profound. Increase in butanol concentration was marginal $(1.51 \%)$ in favor 

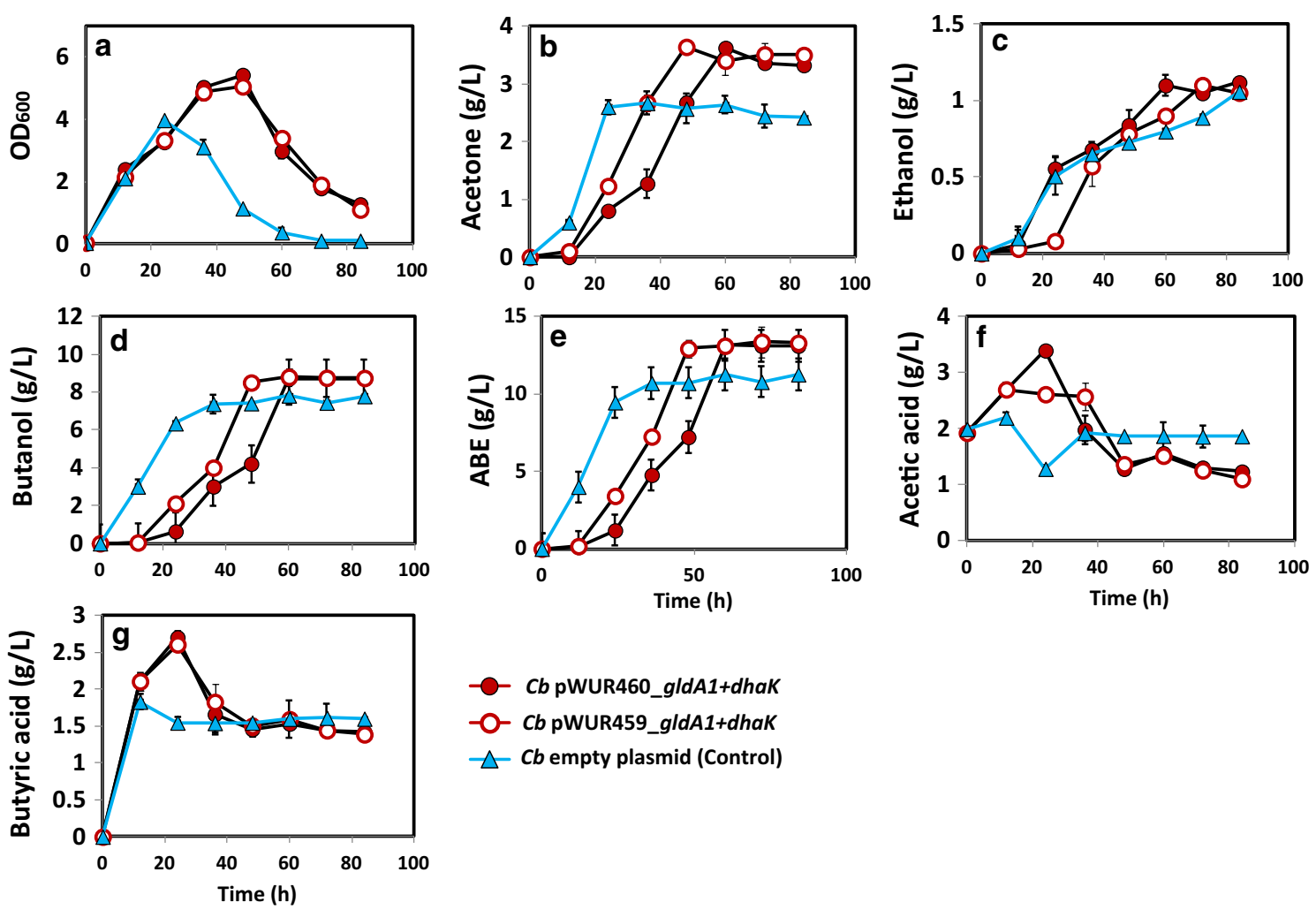

$\triangle C$ Cb empty plasmid (Control)

Fig. 4 Fermentation profiles of Cb pWUR460_gldA1 + dhaK and Cb pWUR459_gldA1 + dhaK during growth on glucose + glycerol medium. a Cell growth in terms of $\mathrm{OD}_{600}, \mathbf{b}$ acetone, $\mathbf{c}$ ethanol, $\mathbf{d}$ butanol, e $\mathrm{ABE}, \mathbf{f}$ acetic acid, $\mathbf{g}$ butyric acid

Table 1 Substrate utilization, ABE productivity and yield of recombinant $C$. beijerinckii (Cb) strains during fermentation of glycerol + glucose medium

\begin{tabular}{|c|c|c|c|c|c|c|c|}
\hline \multirow[t]{2}{*}{ Recombinant $C b$ strain } & \multicolumn{2}{|c|}{ Glycerol utilized } & \multicolumn{2}{|c|}{ Glucose utilized } & \multicolumn{3}{|l|}{ ABE } \\
\hline & Conc. (g/L) & $\begin{array}{l}\% \text { Improvement } \\
\text { vs. control }\end{array}$ & Conc. (g/L) & Rate $(g / L / h)$ & Conc. (g/L) & $X(\mathrm{~g} / \mathrm{L} / \mathrm{h})$ & $Y(\mathbf{g} / \mathbf{g})$ \\
\hline pWUR460_gldA1 & $21.61 \pm 2^{\mathrm{a}}$ & 25.2 & $35.1 \pm 2.3$ & $0.96^{\mathrm{a}}$ & $13 \pm 0.01^{\mathrm{a}}$ & $0.22^{\mathrm{a}}$ & $0.24^{\mathrm{a}}$ \\
\hline pWUR459_gldA1 & $23.1 \pm 2.1^{\mathrm{a}}$ & 33.8 & $34.8 \pm 4.5$ & $1.24^{\mathrm{b}}$ & $12.8 \pm 1.2^{\mathrm{a}}$ & $0.35^{\mathrm{b}}$ & $0.22^{\mathrm{a}}$ \\
\hline pWUR460_dhaD1 & $22 \pm 0.12^{\mathrm{a}}$ & 27.35 & $35 \pm 1.9$ & $1.01^{\mathrm{a}}$ & $13.1 \pm 0.1^{\mathrm{a}}$ & $0.22^{\mathrm{a}}$ & $0.23^{\mathrm{a}}$ \\
\hline pWUR459_dhaD1 & $23.4 \pm 3.1^{\mathrm{a}}$ & 35.5 & $35.1 \pm 1.3$ & $1.3^{b}$ & $13 \pm 0^{\mathrm{a}}$ & $0.22^{\mathrm{a}}$ & $0.23^{\mathrm{a}}$ \\
\hline pWUR460_gldA1+dhak & $23.67 \pm 0^{a}$ & 37.14 & $35.2 \pm 1.2$ & $0.98^{\mathrm{a}}$ & $13.2 \pm 1.1^{\mathrm{a}}$ & $0.22^{\mathrm{a}}$ & $0.22^{\mathrm{a}}$ \\
\hline pWUR459_gldA1 + dhak & $24.4 \pm 0.8^{\mathrm{a}}$ & 41.4 & $35.1 \pm 0.8$ & $1.18^{c}$ & $12.8 \pm 0.7^{\mathrm{a}}$ & $0.36^{b}$ & $0.22^{\mathrm{a}}$ \\
\hline pWUR460_dhaD1+gldA1 & $24.6 \pm 0.1^{\mathrm{a}}$ & 42.94 & $35 \pm 0.2$ & $1.01^{\mathrm{a}}$ & $13.2 \pm 0.1^{\mathrm{a}}$ & $0.28^{\mathrm{a}}$ & $0.22^{\mathrm{a}}$ \\
\hline pWUR459_[(dhaD1 + gldA1) dhaK] & $23.2 \pm 0^{\mathrm{a}}$ & 28.62 & $34.8 \pm 1.2$ & $1.22^{\mathrm{a}}$ & $12.5 \pm 0.5^{\mathrm{a}}$ & $0.26^{\mathrm{a}}$ & $0.22^{\mathrm{a}}$ \\
\hline pMTL500E $P_{a d c}^{(-)} P_{t h l}^{(-)}$(Control) & $17.26 \pm 1^{\mathrm{b}}$ & - & $34.8 \pm 0.8$ & $1.14^{c}$ & $11.3 \pm 0.4^{b}$ & $0.18^{c}$ & $0.22^{\mathrm{a}}$ \\
\hline
\end{tabular}

$X$ productivity; $Y$ yield

$a, b, c$ Fisher's least significant difference $(p<0.1)$ within parameters for each insert versus the plasmid control. Values with same supesrcript are not significantly different $(p<0.1)$

of gldA1+dhaK when compared to gldA1 expressed alone (Table 1). ABE concentrations and productivities were similar for both strains $(\sim 13.2 \mathrm{~g} / \mathrm{L}$ and $0.22 \mathrm{~g} / \mathrm{L} / \mathrm{h}$, respectively).
Contrary to constitutive overexpression where a remarkable difference was observed in cell growth between $C b \_g l d A 1$ and $C b \_g l d A 1+d h a K$, inducible overexpression of gldA1+dhaK increased cell growth by 
only $8 \%$, when compared to $C b \_g l d A 1$. As with the constitutive strains, butanol and ABE concentrations of $C b$ pWUR459_gldA1 + dhaK $(8.81 \mathrm{~g} / \mathrm{L}$ and $12.81 \mathrm{~g} / \mathrm{L}$, respectively) were similar to those of $C b$ pWUR459_gldA1 (8.75, and $12.9 \mathrm{~g} / \mathrm{L}$, respectively; Figs. 3, 4).

\section{Co-expression of $C p$ gldA $1+d h a D 1$ as a fused protein improved cell growth relative to overexpression of the single proteins}

The basis for linking similar proteins that catalyze the same reaction was to amplify the number of active sites per recombinant protein, thereby potentially increasing the efficiency of substrate conversion. Therefore, $C p$ dhaD 1 and gldA1 were covalently tethered with a polyglycine linker, and the gene construct was then cloned into pWUR460 followed by transformation into $\mathrm{Cb}$. We sought to ascertain whether co-expression of two Gldhs as a fused protein would lead to more beneficial effects, when compared to the overexpression of a single Gldh. In an effort to further increase glycerol utilization, as observed with gldA1+dhaK-i.e., concomitant overexpression of $C p$ glycerol dehydrogenase and dihydroxyacetone kinase-the fused $d h a D 1+$ gld $A 1$ was linked to dhaK to generate $[($ dhaD $1+$ gldA 1$)$ dhaK].
Owing to the potentially large size of the resulting insert $[($ dhaD $1+$ gldA 1$)$ dhaK], which may pose some expression problems when overexpressed as single fused protein, dhaK in the construct [(dhaD1+gldA1) dhaK] was designed to be expressed alone as a single protein, while $d h a D 1+g l d A 1$ was expressed as a fused protein. To avoid likely metabolic burden potentially induced by the large size of the resulting recombinant plasmid, overexpression of $[(d h a D 1+$ gld $A 1)$ dhaK $]$ insert was placed under the control of inducible acetoacetate decarboxylase $(a d c)$ promoter, in pWUR459. The newly generated $C b$ strains - $C b$ pWUR460_[dhaD1+gld 1 1] and $C b$ pWUR459_[(dhaD1+gldA1) dhaK]-were used to conduct batch ABE fermentation in glucose+glycerol medium (1:2 molar ratio).

Figure 5 shows the fermentation profiles of $C b$ pWUR460_dhaD1+gldA1 and $C b$ pWUR459_ $[($ dhaD $1+$ gldA1 $)$ dhaK $]$ relative to the plasmid control, without furfural supplementation. The fermentation profiles of $C b$ pWUR460_dhaD1 + gldA1, pWUR460_gldA1, pWUR460_dhaD1, and pWUR460_gldA1+dhaK were compared. Cell growth, butanol, and ABE concentrations increased 59\%, 14\%, and $17.3 \%$, respectively, in $C b$ pWUR460_dhaD1+gldA1 relative to the
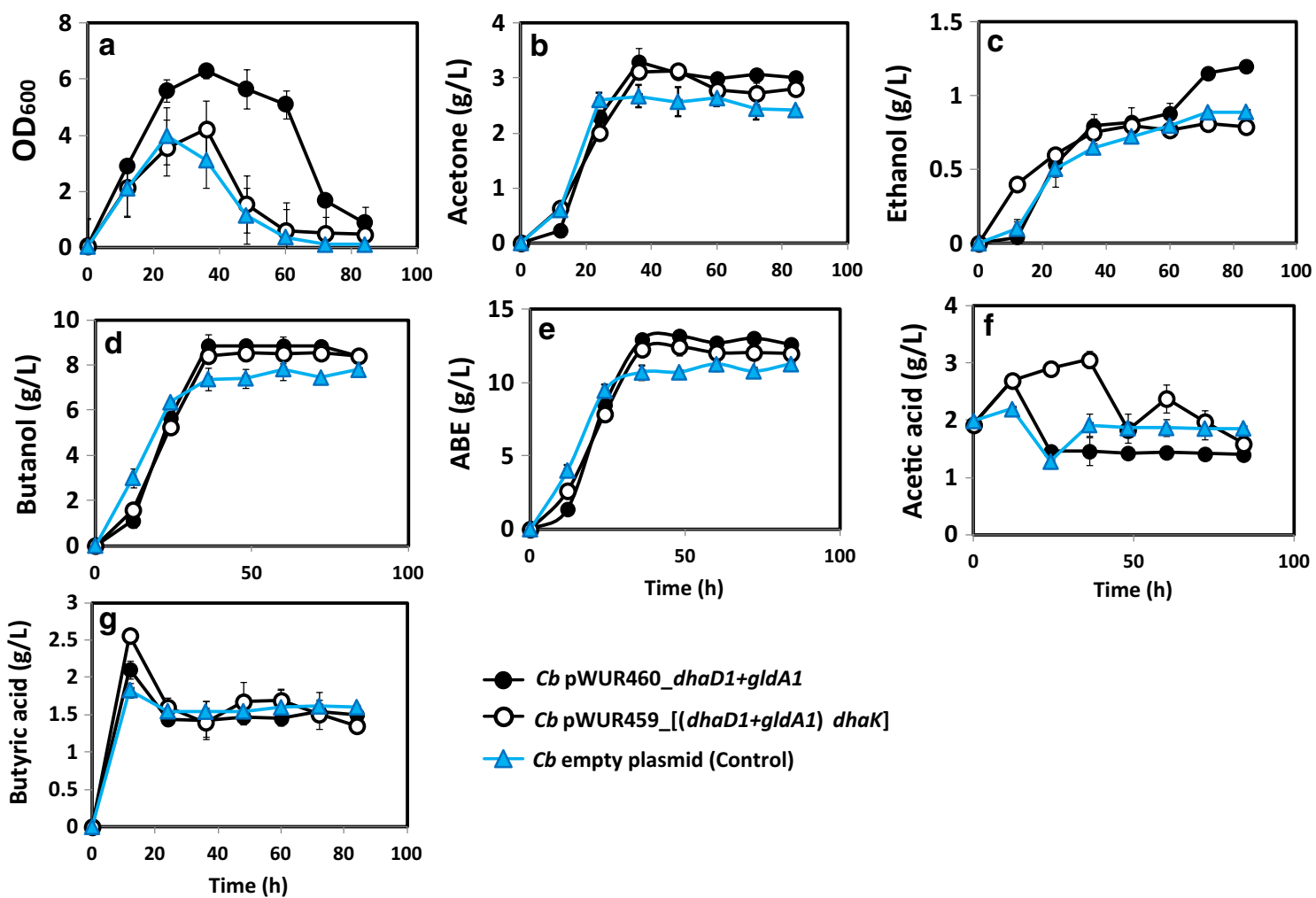

$\triangle C$ Cb empty plasmid (Control)

Fig. 5 Fermentation profiles of Cb pWUR460_dhaD1 + gldA1 and Cb pWUR459_[(dhaD1 + gldA 1) dhaK] during growth on glycerol-supplemented glucose medium. a Cell growth in terms of $\mathrm{OD}_{600}, \mathbf{b}$ acetone, $\mathbf{c}$ ethanol, $\mathbf{d}$ butanol, e $\mathrm{ABE}, \mathbf{f}$ acetic acid, $\mathbf{g}$ butyric acid 
plasmid control (Fig. 5). Likewise, the ABE productivity of $C b$ pWUR460_dhaD1+gldA1 was significantly higher $(55.6 \%)$ when compared to the plasmid control (Table 1). Further, cell growth increased $64 \%$ and 57.5\% in $C b$ pWUR460_dhaD1+gldA1 when compared to pWUR460_dhaD1 and pWUR460_gldA1, respectively. Similarly, butanol concentration and ABE productivity of $C b$ pWUR460_dhaD $1+$ gld $A 1$ increased $\sim 4 \%$ and $27.3 \%$, respectively, relative to $C b$ pWUR460_dhaD1 and pWUR460_gldA1 (Table 1).

$C b$ pWUR460_dhaD1 + gldA1 exhibited $16 \%$ higher cell $\mathrm{OD}_{600}$ when compared to $\mathrm{Cb}$ pWUR460_gldA1+dhaK (Figs. 4a, 5a). Likewise, the ABE productivity of $C b$ pWUR460_dhaD1+gldA1 was $27 \%$ higher than that of $C b$ pWUR460_gldA1+dhaK (Table 1), although the corresponding final butanol and $\mathrm{ABE}$ concentrations $(8.85 \mathrm{~g} / \mathrm{L}$ and $13.2 \mathrm{~g} / \mathrm{L})$ were similar to those of pWUR460_gldA1 + dhaK $(8.72 \mathrm{~g} / \mathrm{L}$ and $13.2 \mathrm{~g} / \mathrm{L})$.

Inducible overexpression of fused [dhaD1+gldA1] with dhaK as in $C b$ pWUR459_[(dhaD1+gldA1) dhaK] increased butanol and total $\mathrm{ABE}$ concentrations, and ABE productivity to $8.83 \%, 12.71 \%$, and $44.4 \%(p<0.1)$, relative to the plasmid control (Table 1 and Fig. 5d, e). Although constitutive overexpression of gldA1 with $d$ haK as a fused protein resulted in significant improvement in cell growth relative to constitutive overexpression of gldA1 alone, there was no similar improvement in cell growth when $[$ dhaD $1+$ gldA1] was overexpressed with dhaK, despite the use of an inducible promoter which was earlier observed to result in higher cell growth (Figs. 2a, $3 a$; perhaps, this was because dhaK was overexpressed as a single protein in $[($ dhaD $1+$ gldA1 $)$ dhaK $]$. Nonetheless, butanol and ABE concentrations of pWUR459_ $[$ dhaD $1+$ gldA 1$]+$ dhaK $(8.52 \mathrm{~g} / \mathrm{L}$ and $12.7 \mathrm{~g} / \mathrm{L})$ were comparable to those of pWUR460_dhaD1+gldA1 $(8.86 \mathrm{~g} / \mathrm{L}$ and $13.18 \mathrm{~g} / \mathrm{L})$, and significantly higher $(p<0.1)$ than the empty plasmid control $(7.81 \mathrm{~g} / \mathrm{L}$ and $11.25 \mathrm{~g} / \mathrm{L}$; Table 1 and Fig. 5d, e).

\section{Glucose and glycerol consumption by recombinant $\mathrm{Cb}$ strains}

Overall, we observed increase in glycerol consumption by recombinant strains of $C b$-overexpressing $C p$ gldh and dhaK genes relative to the plasmid control (Table 1 ). Glycerol consumption by $C b$ pWUR460_gldA1 and $C b$ pWUR460_dhaD1 increased 25\% and 28\%, respectively, when compared to the plasmid control (Table 1). Further improvement in glycerol utilization was observed with $C b$ pWUR460_gldA1+dhaK, which utilized $37.1 \%$ more glycerol than the empty plasmid control. This represents $\sim 10 \%$ increase in glycerol consumption when compared to overexpression of Gldh only.
Constitutive overexpression of two Gldh $[$ dhaD $1+$ gldA1] as a fused protein increased glycerol utilization by $43 \%$ relative to the plasmid control, thus, representing $14 \%$ increase in glycerol consumption relative to overexpression of GldA1 or DhaD1 alone (Table 1). With [(dhaD1+gldA1) dhaK], 28.6\% increase in glycerol utilization was observed (compared to $43 \%$ by dhaD $1+\operatorname{gldA1}$ ), relative to the plasmid control. Although $28.6 \%$ increase is a significant improvement relative to the plasmid control, this increase was still $14 \%$ short of the improvement observed with dhaD1+gldA1.

Although the recombinant strains preferred glucose to glycerol as substrate, as evidenced by complete utilization of glucose after $48 \mathrm{~h}$, we found that the rate of glucose utilization by the plasmid control after $12 \mathrm{~h}$ of fermentation was slightly higher than those of the constitutively expressed (pWUR460) recombinant $C b$ strains (Table 1). For example, the rate of glucose consumption by the plasmid control was $1.2 \mathrm{~g} / \mathrm{L} / \mathrm{h}$, whereas the rates of glucose consumption were $0.96,1.0,0.98$, and $1.0 \mathrm{~g} / \mathrm{L} / \mathrm{h}$ for $\mathrm{Cb}$ pWUR460_gldA1, dhaD1, [gldA1+dhaK], and $[$ dhaD $1+$ gldA1], respectively (Table 1 ). To ascertain whether decreases in the rates of glucose utilization were due to constitutive overexpression of the Gldhs, we determined glucose consumption rates for the inducible overexpression strains. Our results showed that overexpression of Gldhs using the inducible promoter increased the rate of glucose utilization relative to constitutive overexpression and the plasmid control. For example, the rates of glucose consumption by $C b$ pWUR459_gldA1 and $C b$ pWUR459_dhaD1 increased $29.2 \%$ and $8.8 \%$, and $29 \%$ and $14 \%$, relative to their respective constitutive strains and the plasmid control, respectively (Table 1). Also, $C b$ pWUR459_[dhaD1 + gldA1] + dhaK showed $7 \%$ increase in the rate of glucose consumption when compared to the plasmid control (Table 1). The rate of glycerol consumption by the constitutive $C b$ pWUR460_gldA1 after $24 \mathrm{~h}(0.42 \mathrm{~g} / \mathrm{L} / \mathrm{h})$ significantly increased (16.2\%) when compared to the inducible $\mathrm{Cb}$ pWUR459_gldA1 $(0.37 \mathrm{~g} / \mathrm{L} / \mathrm{h})$, which in turn was $9 \%$ higher than plasmid control $(0.34 \mathrm{~g} / \mathrm{L} / \mathrm{h})$.

\section{The activities of glycerol dehydrogenases and dihydroxyacetone kinase in the recombinant $\mathrm{Cb}$ strains}

The Gldh and DhaK activities of the recombinant $C b$ strains were measured in crude cell extracts using cells grown in glucose + glycerol medium. Figure $6 \mathrm{~A}$ shows the Gldh activity of $C b$ pWUR460_dhaD1+gldA1 and the empty plasmid control, $C b$ pMTL500E, while Fig. 6B compares their relative activities to $C p$ Gldh. Overall, the Gldh activity increased significantly in the recombinant 

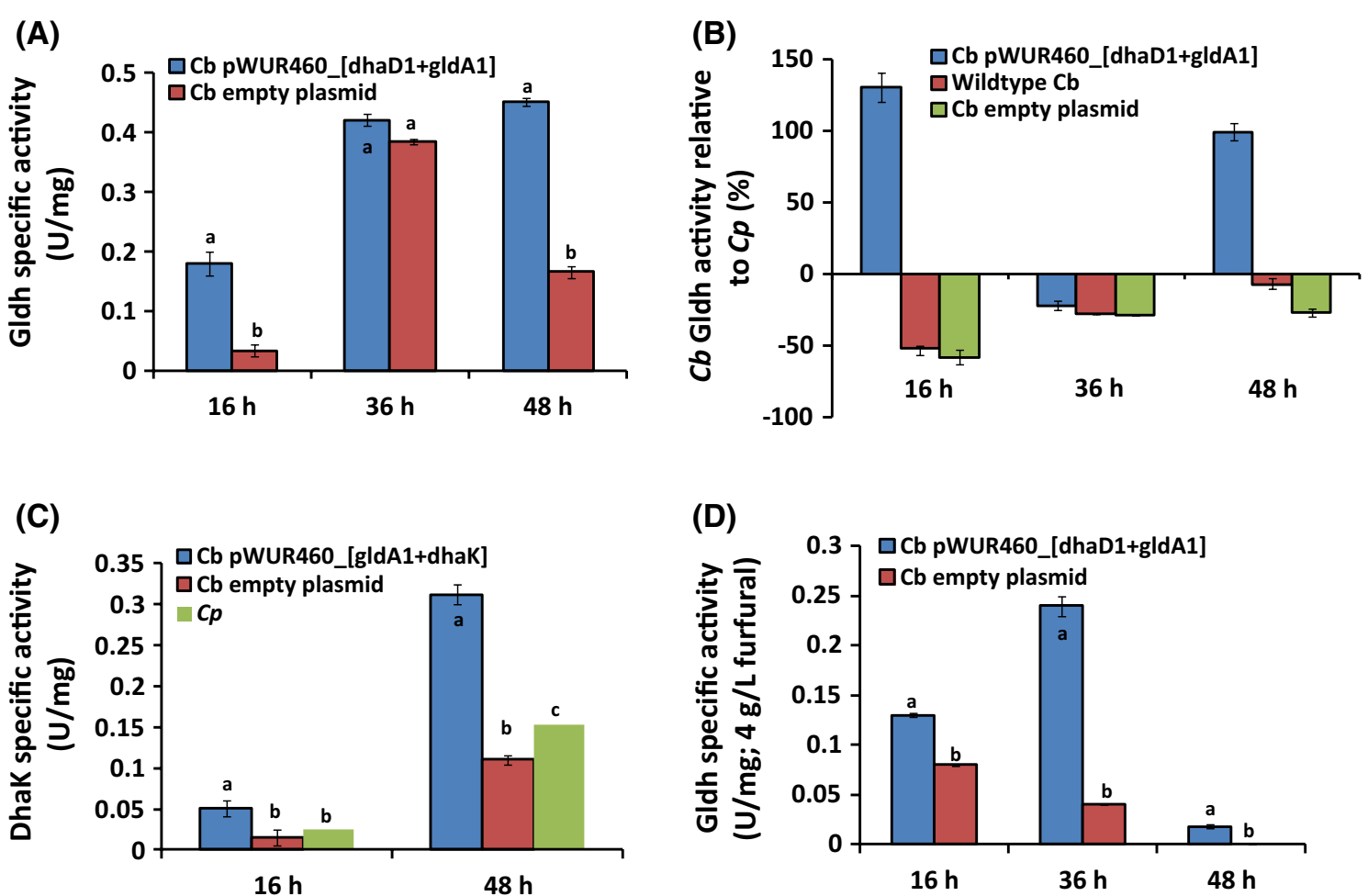

Fig. 6 The activities of Gldh and DhaK in cell-free extracts of recombinant Cb at 16, 36, and 48 h of growth. A Gldh specific activities, B Gldh \% relative activities compared to wild-type Cp Gldh, C DhaK specific activities, D Gldh activity of Cb pWUR460_dhaD1+gldA1 challenged with $4 \mathrm{~g} / \mathrm{L}$ furfural. Different letters (e.g., a, b or $c)$ indicate significance $(p<0.1)$ within each time point

$\mathrm{Cb}$ strains when compared to the empty plasmid control (Fig. 6A).

At 16 and $48 \mathrm{~h}$ of fermentation, Gldh activity of the plasmid control was $51.3 \%$ and $56.7 \%$ lower, respectively, when compared to $C p$ Gldh activity (Fig. 6B). However, overexpression of dhaD $1+\operatorname{gldA} 1$ from $C p$ in $C b$ significantly increased Gldh specific activity by $130.8 \%$ and $99.6 \%$ at 16 and $48 \mathrm{~h}$, respectively, relative to wild-type $C p$ (Fig. 6B). The specific activities of Gldh at $48 \mathrm{~h}$ for $\mathrm{Cb}$ pWUR460_gldA1 and $C b$ pWUR460_dhaD1 (0.34 U/mg and $0.3 \mathrm{U} / \mathrm{mg}$ ) increased twofold when compared to the plasmid control $(0.17 \mathrm{U} / \mathrm{mg})$. At $16 \mathrm{~h}$, the specific Gldh activity of $C b$ pWUR460_dhaD1+gldA1 was 4.5- and 3.7-fold higher than that of the empty plasmid control (Fig. 6A). In addition, the Gldh activity of the strain overexpressing dhaD1 + gldA1 increased 1.5-fold when compared to overexpression of dhaD1 (or gldA1) alone (data not shown).

DhaK specific activity was measured using crude cell extracts of $C b$ pWUR460_gldA1 + dhaK. At $48 \mathrm{~h}$, the DhaK activity was $0.31 \mathrm{U} / \mathrm{mg}$, which was significantly higher (2.4-fold) than that of the plasmid control $(0.11 \mathrm{U} / \mathrm{mg}$;
Fig. 6C). Similarly, the DhaK activity of recombinant $\mathrm{Cb}$ pWUR460_gldA1+dhaK also increased 2.1-fold relative to the wild-type $C b(0.31 \mathrm{U} / \mathrm{mg}$ versus $0.1 \mathrm{U} / \mathrm{mg}$, respectively).

\section{Furfural tolerance of the recombinant $C b$ strains}

We previously studied the beneficial role of glycerol supplementation as a strategy for improving furfural detoxification by $C$. beijerinckii [13]. In the current experiment, we sought to exploit improved glycerol utilization accruing from overexpression of $C p$ gldh and $d h a K$ in $C b$ as a means to further enhance furfural detoxification. Previously, we had observed that simultaneous supplementation of furfural and erythromycin to the fermentation medium severely inhibits the growth of recombinant $C b$ strains. Therefore, the furfural detoxification experiments were conducted with $15 \mu \mathrm{g} / \mathrm{mL}$ erythromycin. Comparative recombinant Gldh activity was measured at midstationary phase $(48 \mathrm{~h})$ in $C b$ pWUR460_dhaD $1+$ gldA 1 and the plasmid control to ascertain recombinant plasmid retention at low erythromycin concentration $(15 \mu \mathrm{g} / \mathrm{mL})$. Indeed, the Gldh activity of $C b$ pWUR460_dhaD $1+$ gld $A 1$ 
in the fermentation medium was significantly higher (2.5fold) than that of the plasmid control.

Since $C b$ pWUR460_dhaD $1+$ gldA1 produced a better fermentation profile than $C b$ pWUR460_gldA1 (or dhaD1) and $C b$ pWUR460_gldA1+dhaK, this strain was selected for fermentation of furfural-challenged glucose + glycerol medium. The use of a constitutive promoter to drive gene expression as in $C b$ pWUR460_dhaD1+gldA1 was intended to ensure glycerol utilization from the onset of cell growth, thereby potentially increasing the availability of reducing equivalents crucial to furfural detoxification and butanol formation.

Figure 7 and Table 2 show cell growth, butanol and $\mathrm{ABE}$ production by furfural $(2,3,4,5$, and $6 \mathrm{~g} / \mathrm{L})$-challenged $\mathrm{Cb}$ pWUR460_dhaD1+gldA1. Cell growth increased 55.7, 40.8, 49.2, 45.9, and 30.4\% with 2, 3, 4, 5 and $6 \mathrm{~g} / \mathrm{L}$ furfural treatments, respectively, when compared to the plasmid control. Similarly, butanol concentrations increased 3.4, 10.3, 11.8, and $45.5 \%(p<0.1)$ in 3, 4,5 , and $6 \mathrm{~g} / \mathrm{L}$ furfural-challenged cultures, respectively, when compared to the empty plasmid control (Fig. 7 and Table 2). Likewise, ABE concentration increased 7.6, 6.3, and $40.2 \%$ with 4,5 , and $6 \mathrm{~g} / \mathrm{L}$ furfural challenge, respectively, relative to the control (Fig. 7 and Table 2). In fact, the presence of 2,3 , and $4 \mathrm{~g} / \mathrm{L}$ furfural increased glycerol consumption by both $C b$ pWUR460_dhaD1 + gldA1 and the plasmid control, when compared to cultures not supplemented with furfural (data not shown). With 3 and $4 \mathrm{~g} / \mathrm{L}$ furfural challenge, $\sim 20 \mathrm{~g} / \mathrm{L}$ glycerol was utilized by the plasmid control; whereas, $C b$ pWUR460_dhaD1 + gldA1 consumed a total of $30 \mathrm{~g} / \mathrm{L}$ glycerol, representing $45 \%$ increase in glycerol consumption (Table 2). Similarly, glycerol consumption increased $63 \%$ and $77 \%$ with 5 and $6 \mathrm{~g} / \mathrm{L}$ furfural treatments, respectively, relative to the plasmid control. With $6 \mathrm{~g} / \mathrm{L}$ furfural, the ABE productivity of $C b$ pWUR460_dhaD $1+$ gld $A 1$ increased $40 \%$ relative to the plasmid control (Table 2).

The rates of furfural detoxification by $\mathrm{Cb}$ pWUR460_dhaD1+gldA1 and the plasmid control were similar with 2,3 and $4 \mathrm{~g} / \mathrm{L}$ furfural challenge (1.36 and $1.37 \mathrm{~g} / \mathrm{L} / \mathrm{h}$, respectively, with $2 \mathrm{~g} / \mathrm{L}$ furfural treatment, 1.36 and $1.4 \mathrm{~g} / \mathrm{L} / \mathrm{h}$, respectively, with $3 \mathrm{~g} / \mathrm{L}$ furfural treatment, and 1.15 and $1.13 \mathrm{~g} / \mathrm{L} / \mathrm{h}$, respectively, with $4 \mathrm{~g} / \mathrm{L}$ furfural treatment). However, with 5 and $6 \mathrm{~g} / \mathrm{L}$ furfural treatments, the rates of furfural detoxification by $C b$ pWUR460_dhaD $1+$ gldA 1 were $1.38 \mathrm{~g} / \mathrm{L} / \mathrm{h}$ and $1.24 \mathrm{~g} / \mathrm{L} / \mathrm{h}$, respectively; while the rates for the plasmid control were $0.82 \mathrm{~g} / \mathrm{L} / \mathrm{h}$ and $0.96 \mathrm{~g} / \mathrm{L} / \mathrm{h}$, respectively (Table 2). These represent remarkable increases $(67.9 \%$ and $29.2 \%)$ in the rates of furfural detoxification with $5 \mathrm{~g} / \mathrm{L}$ and $6 \mathrm{~g} / \mathrm{L}$ furfural, respectively, by $\mathrm{Cb}$ pWUR460_dhaD1+gldA1.
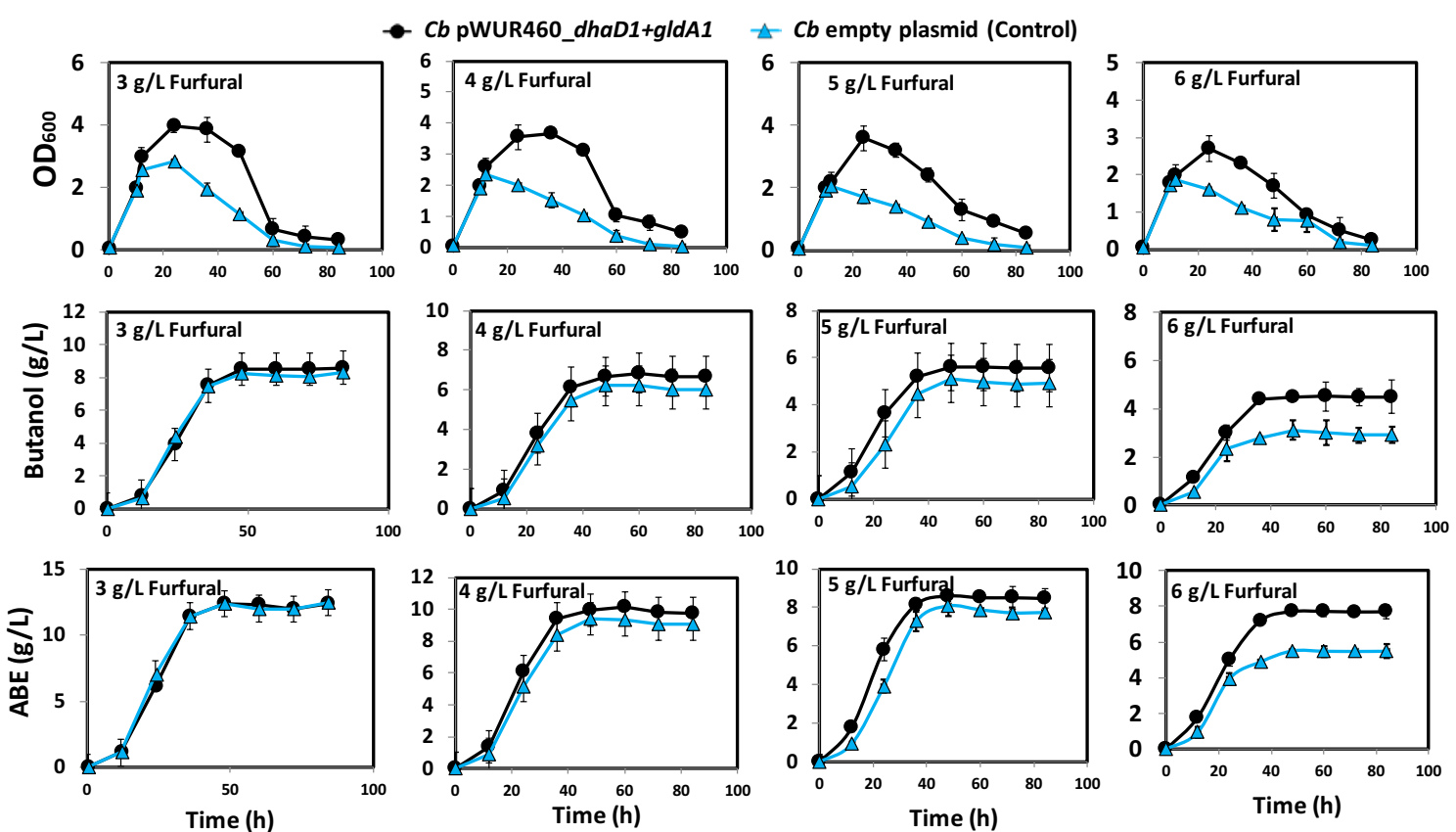

Fig. 7 Fermentation profiles of $\mathrm{Cb}$ pWUR460_dhaD1+gldA1 during growth on glycerol-supplemented glucose medium challenged with 3, 4, 5, or $6 \mathrm{~g} / \mathrm{L}$ furfural. Panel 1: Growth profiles at 3, 4, 5, $6 \mathrm{~g} / \mathrm{L}$ furfural treatment. Panel 2: Butanol concentrations at 3, 4, 5, $6 \mathrm{~g} / \mathrm{L}$ furfural treatment. Panel 3: Total ABE concentrations at 3,4,5,6 g/L furfural treatment 


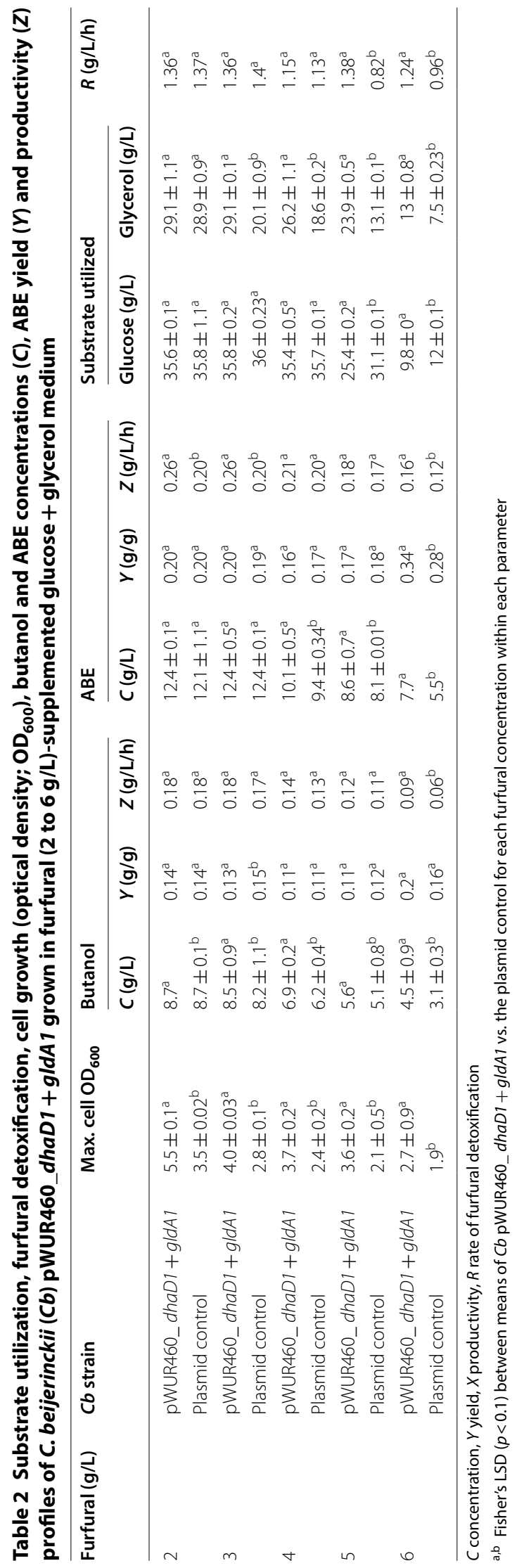


The role of glycerol supplementation in facilitating furfural detoxification was evident when the detoxification rates were compared with that of furfuralchallenged glucose-only medium. Specifically, furfural detoxification rates were lower for glucose-only medium when compared to glycerol+glucose medium. For example, the rates of furfural detoxification by $C b$ pWUR460_dhaD1 + gldA1 in glucose-only medium supplemented with 4,5 , and $6 \mathrm{~g} / \mathrm{L}$ furfural were $0.77,0.87$, and $0.96 \mathrm{~g} / \mathrm{L} / \mathrm{h}$, respectively. Comparing these rates with $1.15,1.38$ and $1.24 \mathrm{~g} / \mathrm{L} / \mathrm{h}$ obtained with glycerol-supplemented P2 medium challenged with 4,5 and $6 \mathrm{~g} / \mathrm{L}$ furfural shows $49.4,58.6$, and $29.2 \%$ improvements, respectively, in the rates of furfural detoxification.

Gldh activity of $C b$ pWUR460_dhaD1+gldA1 was determined during fermentation of $4 \mathrm{~g} / \mathrm{L}$ furfuralchallenged glucose + glycerol medium (1:2 molar ratio; Fig. 6D). At 16 and $36 \mathrm{~h}$ of growth, Gldh activity of $\mathrm{Cb}$ pWUR460_dhaD1+gldA1 increased $\sim$ twofold relative to the empty plasmid control. Interestingly, at $48 \mathrm{~h}$ of growth, the empty plasmid control exhibited undetectable Gldh activity, while $C b$ pWUR460_dhaD $1+$ gld $A 1$ showed Gldh activity of $0.018 \mathrm{U} / \mathrm{mg}$, thereby implicating overexpression of the recombinant protein in the payoffs observed with glycerol-supplemented furfural-challenged fermentations by $C b$ pWUR460_dhaD $1+$ gld $A 1$.

$C b$ pWUR459_[(dhaD1+gldA1) dhaK ] was also used to ferment glucose+glycerol medium supplemented with $15 \mu \mathrm{g} / \mathrm{mL}$ erythromycin at $0 \mathrm{~h}$, and then challenged with $3,4,5$, or $6 \mathrm{~g} / \mathrm{L}$ furfural at $12 \mathrm{~h}$ of fermentation. Because inducible $a d c$ promoter from $C$. acetobutylicum triggers recombinant protein overexpression at early solventogenic phase when sufficient cell biomass has accumulated (18 h; [25]), pWUR459 plasmid was chosen for the overexpression of the large recombinant proteins [(DhaD1 + GldA1) DhaK]. The rationale was to minimize the combined metabolic burden of plasmid replication and furfural toxicity by first accumulating sufficient cell biomass prior to the inception of recombinant protein overexpression and furfural challenge. Notably, adc promoter is induced in solventogenic Clostridium species at late exponential growth phase during which remarkable amounts of acetic and butyric acid are produced and accumulated by the microorganisms, thus facilitating the switch from acidogenesis to solventogenesis, causing shift from acid accumulation to acid assimilation for solvent biosynthesis [26, 27]. As a result, the $a d c$ promoter does not require additional exogenous inducer to be turned on, and it is largely functional during the solventogenic growth phase. Figure 8 shows the fermentation profile of $C b$ pWUR459_[(dhaD1+gldA1) dhaK] in the presence of 4,5 , and $6 \mathrm{~g} / \mathrm{L}$ furfural. At $24 \mathrm{~h}$ of growth, cell OD was 1.4-, 2.1-, and 2.6-folds at 4, 5 , and $6 \mathrm{~g} / \mathrm{L}$ furfural challenge, respectively, when compared to the plasmid control. With $4 \mathrm{~g} / \mathrm{L}$ furfural, butanol and $\mathrm{ABE}$ concentrations increased $13.9 \%$ and $14.5 \%$, relative to the plasmid control. Similarly, with 5 and $6 \mathrm{~g} / \mathrm{L}$ furfural, butanol and $\mathrm{ABE}$ concentrations increased $86.8 \%$ and $78.1 \%$, and $53.8 \%$ and $52.2 \%$, respectively, when compared to the plasmid control (Fig. 8).

\section{Discussion}

This study was designed to achieve the following objectives: (i) to metabolically engineer $C b$ strains through systematic overexpression of $C p$ gldh and $d h a K$ to generate glycerol-utilizing $\mathrm{Cb}$ strains, (ii) to characterize the phenotypes of the resulting recombinant $C b$ strains in terms of cell growth, ABE production, and glycerol utilization, and (iii) to ascertain whether increased consumption of glycerol translates into increased rate of furfural detoxification and $\mathrm{ABE}$ production. To achieve the above objectives, we first overexpressed $C p$ gldA1 and $d h a D 1$ as single proteins in $C b$. Although there was no difference in the fermentation profiles of both strains, overexpression of each gene in $\mathrm{Cb}$ enhanced glycerol utilization relative to the plasmid control (25\%). This, therefore, suggests that $C p$ glycerol dehydrogenases have specifically evolved to favor glycerol catabolism relative to the single native glycerol dehydrogenase in $C b$. Whereas this contributes, at least in part, to the superior glycerol utilization by $C p$, when compared to other Clostridium species, the overall glycerol utilization capacity of the resulting recombinant $\mathrm{Cb}$ strains-which consumed considerably less glycerol than $C p$-suggests that additional factors beyond individual expression of glycerol dehydrogenases in $C p$ contribute to glycerol utilization by this microorganism $(C p)$.

To further improve glycerol utilization, therefore, we overexpressed gldA1 with DhaK as a fused protein and observed a $37.1 \%$ increase in glycerol utilization when compared to the plasmid control (a further $10 \%$ increase when compared to gldA1 alone). Clearly, the underpinning for this additional payoff accrued from the recombinant DhaK activity. Simultaneous expression of a Gldh and a DhaK from $C p$ in $C b$ was expected to significantly increase flux through the glycerol metabolic shunt, which feeds into the glycolytic pathway, thereby improving growth and $\mathrm{ABE}$ production. However, whereas coexpression of Gldh and DhaK from $C p$ increased growth, $\mathrm{ABE}$ production and glycerol utilization in $\mathrm{Cb}$, when compared to the plasmid control, this did not lead to significant increases relative to co-expression of two Gldhs from $C p$ (DhaD1 + GldA1) in $C b$. In fact, by overexpressing the two Gldh genes (dhaD1 and gldA1) as a fused protein, we further increased glycerol utilization (to a maximum of 43\%), relative to the plasmid control and gldA1 alone, although cell growth, $\mathrm{ABE}$ production and most crucially, glycerol consumption were considerably 

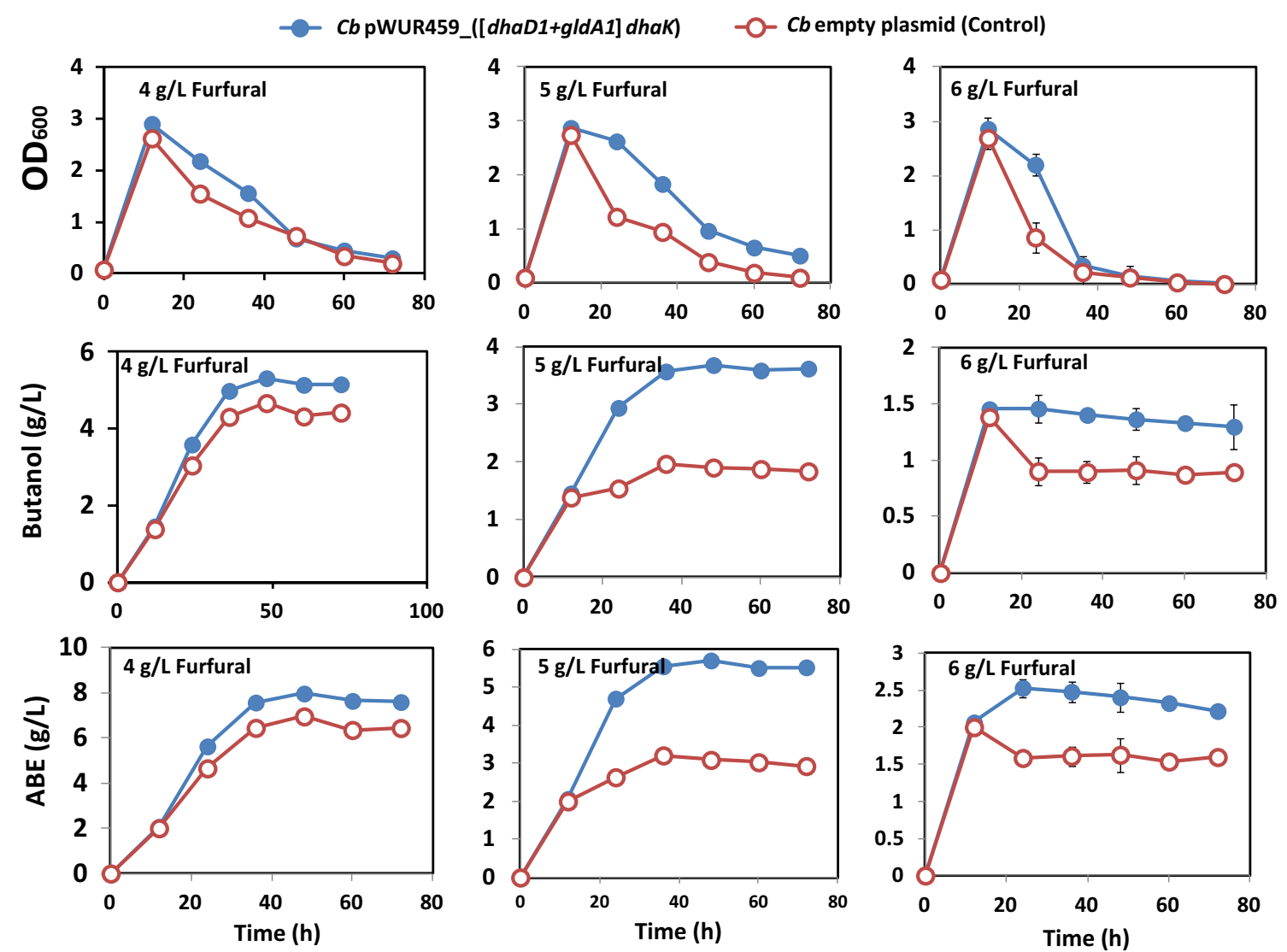

Fig. 8 Fermentation profiles of Cb pWUR459_[(dhaD1 + gldA1) dhaK] during growth on glycerol-supplemented glucose medium challenged with 4, 5, or $6 \mathrm{~g} / \mathrm{L}$ furfural. Panel 1: $\mathrm{OD}_{600}$ at 4, 5, $6 \mathrm{~g} / \mathrm{L}$ furfural treatment. Panel 2: Butanol concentrations at 4, 5, $6 \mathrm{~g} / \mathrm{L}$ furfural treatment. Panel 3: Total $\mathrm{ABE}$ concentrations at $4,5,6 \mathrm{~g} / \mathrm{L}$ furfural treatment

similar among recombinant $\mathrm{Cb}$ strains expressing two fused Gldhs (DhaD1+GldA1) and those expressing a Gldh and a DhaK (GldA1+ DhaK).

Clearly, by combining the catalytic machinery of two Gldhs or a Gldh and a DhaK from $C p$, we further increased glycerol utilization by $C b$, as opposed to expressing one Gldh from $C p$ in $C b$. In light of this, it does appear that the multiplicity of glycerol catabolic genes in $C p$, particularly Gldhs may account, in part for its superior glycerol metabolism relative to other solventogenic Clostridium species. However, it is not clear if all or some of the multiple Gldhs in $C p$ are simultaneously expressed. It would be instructive, therefore, to characterize the expression profiles of Gldhs in $C p$. Interestingly, co-expression of dhaK with dhaD1 + gldA1 did not increase glycerol utilization any further. The observation that the native DhaK activity in C. butyricum is inducible $[4,28]$ indicates that dhaK overexpression in $C b$ may not be critical to drive metabolic flux through the glycerol catabolic shunt, and subsequently towards butanol biosynthesis. More importantly, this suggests that the step catalyzed by Gldh in glycerol metabolism might be the rate-limiting step in glycerol catabolism. This, perhaps explains why $C p$, a potent utilizer of glycerol, evolved multiple copies of gldh genes to promote glycerol catabolism, while harboring a single copy of dhak as in $C b$. Notably, co-expression of dhaK with $d h a D 1+$ gldA1 significantly reduced cell growth when compared to expression of Gldhs alone, or two Gldhs simultaneously, or Gldh and DhaK as a fused protein, although $\mathrm{ABE}$ production was not affected (in the strain expressing dhaK with $d h a D 1+$ gldA1). Perhaps, the large size of the construct $[($ dhaD $1+$ gldA 1$)$ dhaK $]$ expressed in this strain $(10,745 \mathrm{bp})$ may have exerted a degree of metabolic burden on this strain, leading to reduced growth. Notably, glycerol utilization and $\mathrm{ABE}$ production were not affected in this strain $\left(C b_{-}[(d h a D 1+\right.$ gldA 1$\left.) d h a K]\right)$. This indicates that expression of the respective glycerol catabolic genes in this strain, hence flux via the glycerol metabolic shunt, and glycolysis downstream and subsequently towards the ABE pathway were unaffected. Perhaps, metabolic modulations elsewhere, stemming from the expression of a plasmid-borne, large-sized construct impaired growth in $C b_{-}[(d h a D 1+$ gldA1) dhaK]. 
To investigate whether enhanced glycerol utilization due to overexpression of gldhs would promote furfural tolerance in $C b$, the recombinant strains were exposed to furfural. Studies have shown that the toxic effects of furfural on microbial physiology include inhibition of specific enzymes and $\mathrm{NAD}(\mathrm{P}) \mathrm{H}$ depletion $[11,22,29]$. In light of this, we measured the activity of $\mathrm{NAD}(\mathrm{P})$ $\mathrm{H}$-generating Gldh in crude cell extracts of $\mathrm{Cb}$ grown in furfural-supplemented glycerol + glucose medium. Interestingly, the Gldh activity of $C b \_d h a D 1+$ gldA 1 exposed to $4 \mathrm{~g} / \mathrm{L}$ furfural was remarkably higher than that of the plasmid control (Fig. 6D). Based on this, we conclude that the significant payoffs in furfural tolerance in the recombinant $C b$ strains relative to the control were due to overexpression of glycerol catabolic genes (dhaD $1+$ gldA 1 and [(dhaD1+gldA1) dhaK]), leading to enhanced glycerol consumption, and consequently, excess reducing equivalents for furfural detoxification and butanol production (Additional file 1: Figure S4, Table 2). In fact, recombinant $\mathrm{Cb}$ strains demonstrated more rapid rates of furfural reduction to the less toxic furfuryl alcohol, especially with increasing furfural concentration. For instance, whereas $C b$ pWUR460_dhaD1+gldA1 and the empty plasmid control showed similar rates of furfural reduction with 2 and $3 \mathrm{~g} / \mathrm{L}$ furfural, the rates of furfural reduction by $C b$ pWUR460_dhaD1+gldA 1 were $67.9 \%$ and $29.2 \%$ greater than those of the empty plasmid with 5 and $6 \mathrm{~g} / \mathrm{L}$ furfural, respectively (Additional file 1: Figure S4).

\section{Conclusions}

Our results demonstrate that overexpression of $C p$ dhaD1 and gldA1 either as single or a fused protein or in combination with $d h a K$ enhanced glycerol consumption and improved furfural tolerance by the recombinant $C b$ strains. Despite improved glycerol consumption by the recombinant $\mathrm{Cb}$ strains during growth in a glucose + glycerol medium, there were no marked increases in cell optical density during the growth of these strains in a glycerol-only medium (data not shown). Clearly, the inability of $\mathrm{Cb}$ to metabolize glycerol as a sole substrate stems from other factors beyond the lack of superior glycerol catabolic enzymes (such as those found in $C p$ ). One of such factors is the likely absence of a short excess $\mathrm{NAD}(\mathrm{P}) \mathrm{H}$-dissipation pathway during oxidation of glycerol as sole source of carbon by $\mathrm{Cb}$. Clostridium species that utilize glycerol as a sole carbon source (e.g., $C p$ and $C$. butyricum) typically possess the 1,3-propanediol and/or 1,2-propanediol biosynthesis pathway that allows for efficient disposal of excess $\mathrm{NAD}(\mathrm{P}) \mathrm{H}$ generated from glycerol oxidation (Fig. 1). Perhaps, expressing the two-step 1,3-propanediol pathway alongside Gldh and DhaK in $C b$ might confer on $C b$, the ability to metabolize glycerol as a sole carbon source. Given the current crude glycerol glut as a result of the rapidly expanding biodiesel industry and also the generation of microbial inhibitory compounds during lignocellulosic biomass pretreatment, the findings reported here represent a significant progress towards engineering $C b$ strains capable of efficient glycerol metabolism and detoxification of lignocellulose-derived inhibitor, with concomitant production of butanol.

\section{Materials and methods}

\section{Microorganisms and culture conditions}

Clostridium beijerinckii NCIMB 8052 ( $C b$; ATCC 51743) and Clostridium pasteurianum (Cp; ATCC 6013) were obtained from the American Type Culture Collection (Manassas, VA). Laboratory stocks of these microorganisms were maintained as spore suspensions in sterile, double-distilled water at $4{ }^{\circ} \mathrm{C} . \mathrm{Cb}$ and $C p$ spores were revived and propagated as previously described [30]. Spores $(200 \mu \mathrm{L})$ were heat-shocked at $75{ }^{\circ} \mathrm{C}$ for $10 \mathrm{~min}$, cooled on ice for $2 \mathrm{~min}$, and then inoculated into $10-\mathrm{mL}$ anoxic tryptone-glucose-yeast extract (TGY) medium. $\mathrm{Cb}$ and $\mathrm{Cp}$ cultures were incubated at $35^{\circ} \mathrm{C}$ in an anaerobic chamber (Coy Laboratory Products, Inc., Ann Arbor, MI) with a modified atmosphere of $82 \% \mathrm{~N}_{2}, 15 \% \mathrm{CO}_{2}$, and $3 \% \mathrm{H}_{2}$ until optical density $\left(\mathrm{OD}_{600}\right)$ reached $\sim 0.9-1.1$ [30]. Actively growing cultures $(10 \%, \mathrm{v} / \mathrm{v})$ were subsequently transferred to fresh TGY medium and incubated for 3-4 $\mathrm{h}$ (until cultures reached an $\mathrm{OD}_{600} \sim 1.1$ ) to increase the pre-culture volume.

Escherichia coli DH5 $\alpha(E c)$ from New England Biolabs (Ipswich, MA) was used to maintain recombinant plasmids. Ec DH5 $\alpha$ strains carrying recombinant plasmids were grown aerobically by incubation in shaken flasks at $25^{\circ} \mathrm{C}$ and $144 \mathrm{rpm}$ for $16 \mathrm{~h}$ in Lysogeny broth (LB) containing ampicillin $(50 \mu \mathrm{g} / \mathrm{mL})$.

\section{Generation of recombinant glycerol dehydrogenase (dhaD1 and gldA1) and dihydroxyacetone kinase (dhaK) gene constructs}

$\mathrm{Gly}_{5}$ peptide linker was used to covalently tether the $C p$ genes. Protein secondary structure prediction was performed using an online software-Protein Homology/ analogy Recognition Engine (Phyre ${ }^{2}$ version 2.0; Structural Bioinformatics Group, Imperial College, London) to determine which terminus to include the $\mathrm{Gly}_{5}$ peptide linker. Inclusion of $\mathrm{Gly}_{5}$ peptide linker at the appropriate end allows sufficient gap between adjacent proteins and minimizes protein misfolding following expression of recombinant proteins.

We performed protein alignment using the NBCI Blast $p$ algorithm and Visual Molecular Dynamics software (VMD version 1.9.1; Theoretical and Computational 


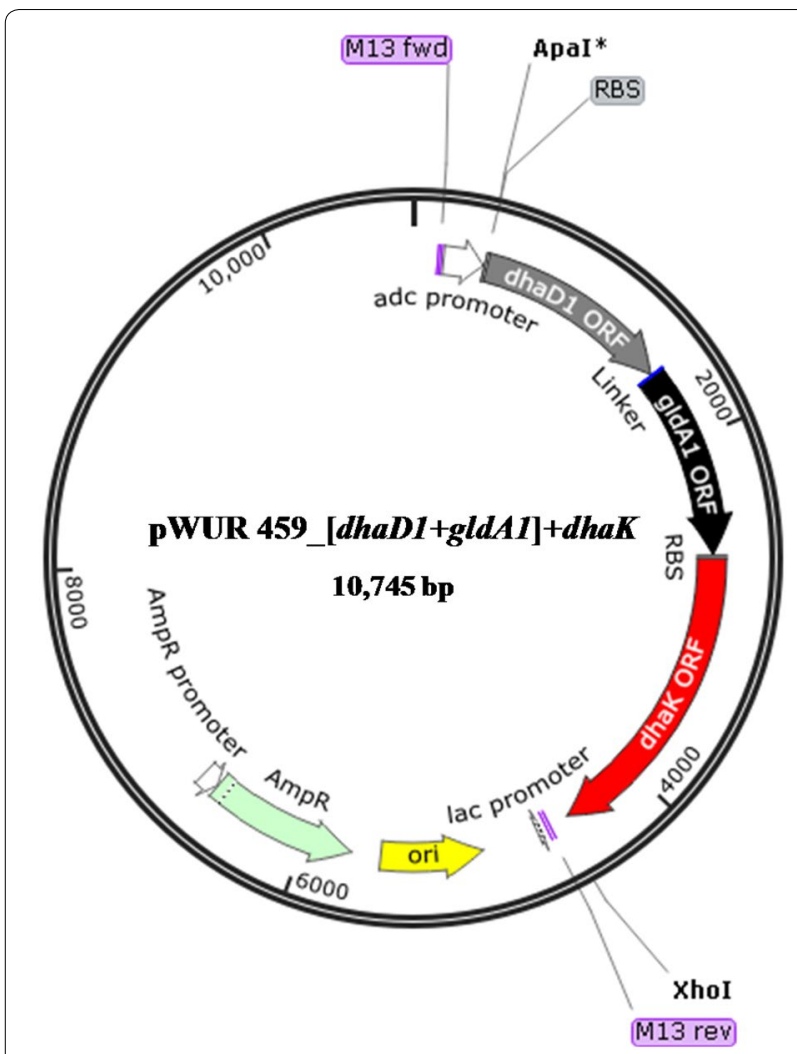

Fig. 9 Schematic representation of recombinant plasmid bearing the construct Cb pWUR459_[(dhaD1 + gldA1) dhaK]. All constructs were generated based on the same plan. The recombinant $\mathrm{Cb}$ strains bearing constitutively expressed constructs were based on the plasmid pWUR460, which bears the constitutive thiolase promoter, whereas pWUR459 bears inducible adc promoter

Biophysics Group, University of Illinois at Urbana-Champaign) to compare primary and secondary structures, respectively, among $C p$ Gldhs, and between $C p$ and $C b$ DhaK (Additional file 1: Table S2). The VMD software generates a root mean square deviation (RMSD) value that predicts the similarity between secondary structures of two proteins (Additional file 1: Tables S1, S2, S3). Proteins with closely matched secondary structures, when aligned, are expected to have lower RMSD value (e.g., dhaD1 and gldA1 in Additional file 1: Table S2).

The DNA sequences for $C p d h a D 1, \operatorname{gldA1}$, and $d h a K$ were obtained from the EMBL-European Bioinformatics Institute and then cloned systematically into $C b$ expression plasmids. Nested PCR and splicing by overlap extension (SOE) PCR were used to amplify each gene from $C p$ gDNA to generate the fused gene constructs. Primers were designed to introduce a Gly 5 peptide linker and a ribosome binding site, and to facilitate cloning of the fused gene construct into the Clostridium-Ec shuttle plasmids pWUR459 and pWUR460 at both the 5' ApaI or NcoI site and the $3^{\prime}$ EcoRI or XhoI site (Fig. 9). Primer sequences are listed in Additional file 1: Table S4. All PCR reactions were performed using PrimeSTAR GXL DNA polymerase (Clontech, Mountain View, CA) and an iCycler $^{\mathrm{TM}}$ Thermal Cycler (Bio-Rad, Hercules, CA). Each $50-\mu \mathrm{L}$ reaction contained $1 \mathrm{X}$ PrimeSTAR GXL buffer, $250 \mu \mathrm{M}$ dNTPs, $0.5 \mu \mathrm{M}$ primers, $\sim 5 \mathrm{ng} / \mu \mathrm{L}$ DNA template, and 1.25 U PrimeSTAR GXL DNA Polymerase.

The cycling conditions for the nested PCR reactions used to amplify each gene from $C p$ gDNA were: (1) $98^{\circ} \mathrm{C}$ for $2 \mathrm{~min}$ (initial denaturation), (2) five cycles of $98{ }^{\circ} \mathrm{C}$ for $20 \mathrm{~s}$, Annealing temperature 1 (AT1-of the portion of primer that anneals to gDNA) for $20 \mathrm{~s}, 72{ }^{\circ} \mathrm{C}$ for $30 \mathrm{~s}$, (3) 30 cycles of $98{ }^{\circ} \mathrm{C}$ for $20 \mathrm{~s}$, annealing temperature 2 (AT2-of entire primer sequence) for $20 \mathrm{~s}, 72{ }^{\circ} \mathrm{C}$ for $30 \mathrm{~s}$ (denaturation, annealing, and extension); (4) $72{ }^{\circ} \mathrm{C}$ for $5 \mathrm{~min}$ (final extension); and (5) $4{ }^{\circ} \mathrm{C}$ for $10 \mathrm{~min}$. The fused gene constructs were assembled using a modified twostep SOE-PCR [31]. In Step 1 SOE-PCR, gene 1 and gene 2 PCR amplicons (e.g., dhaD1 and dhaK) from the nested PCR reactions served as both primers and templates (forward- and reverse- templating fragments, respectively), which generated the fused gene construct (i.e., $[$ dhaD $1+$ dhaK $])$. Cycling conditions for Step 1 SOEPCR were: (1) $98{ }^{\circ} \mathrm{C}$ for $2 \mathrm{~min}$; (2) 15 cycles of $98{ }^{\circ} \mathrm{C}$ for $1 \mathrm{~min}$, annealing temperature of overlap region [nucleotide sequence in the region where the two genes were linked] for $2 \mathrm{~min}, 72{ }^{\circ} \mathrm{C}$ for $3 \mathrm{~min}$; (3) $72{ }^{\circ} \mathrm{C}$ for $10 \mathrm{~min}$; (4) $4{ }^{\circ} \mathrm{C}$ for $10 \mathrm{~min}$. The forward primer for gene 1 (e.g., dhaD1-F) and the reverse primer for gene 2 (e.g., dhaK-R) were then added to the Step 1 SOE-PCR reaction, and the following cycling conditions were used for Step 2 SOEPCR: (1) $98^{\circ} \mathrm{C}$ for $2 \mathrm{~min}$; (2) 30 cycles of $98^{\circ} \mathrm{C}$ for $1 \mathrm{~min}$, annealing temperature of primer pair for $2 \mathrm{~min}, 72^{\circ} \mathrm{C}$ for $3 \mathrm{~min}$; (3) $72{ }^{\circ} \mathrm{C}$ for $5 \mathrm{~min}$; (4) $4{ }^{\circ} \mathrm{C}$ for $10 \mathrm{~min}$.

Each insert (dhaD1, gldA1, gldA1+dhaK, dhaD1 + gldA1, [(dhaD1+gldA1) dhaK]) was then spliced into the Clostridium-Ec shuttle plasmids, pWUR460 or pWUR459, to permit transcription by a constitutive thiolase promoter or inducible acetoacetate decarboxylase promoter (from C. acetobutylicum), respectively [25]. Representative schematics of recombinant plasmids are shown in Fig. 9 and Additional file 1: Figure S1.

In summary, $C p$ dhaD1 and gldA1, which exhibit the closest secondary structure similarity among $C p$ gldhs, were tethered at their C-terminus and N-terminus, respectively, to generate a fused construct $[$ dhaD $1+\operatorname{gld} A 1]$. The insert was then spliced into each of pWUR460 and pWUR459. Furthermore, dhaD1 and gldA1 were separately tethered to $d h a K$ at their $\mathrm{C}$-and $\mathrm{N}$-termini, respectively, to generate [dhaD $1+$ dhaK] and $[g l d A 1+d h a K]$, which were then spliced into both pWUR460 and pWUR459. Further, the fused gldh construct $[d h a D 1+$ gldA1] was linked to dhaK to create 
$[(d h a D 1+g l d A 1) d h a K]$, which was then spliced into pWUR459 for inducible expression as a fused protein. Additionally, dhaD1 and gldA1 inserts were separately spliced into pWUR460 and pWUR459 to be expressed as single (unfused) Gldh proteins.

\section{Restriction digestion and ligation of PCR amplicons into pWUR459/460 plasmid vectors}

Plasmids and amplicons were digested with ApaI and XhoI, respectively (New England Biolabs, Ipswich, MA). A $50-\mu \mathrm{L}$ digestion reaction consisted of nuclease-free water, Cutsmart buffer (5 $\mu \mathrm{L}$; New England Biolabs, Ipswich, MA), ApaI $(1 \mu \mathrm{L})$, and DNA samples $(0.02 \mu \mathrm{g} /$ $\mathrm{mL}$ ). After overnight incubation at $25^{\circ} \mathrm{C}, 1 \mu \mathrm{L} \mathrm{XhoI}$ was added to the reaction and then incubated at $37^{\circ} \mathrm{C}$ for $4 \mathrm{~h}$. The digested vectors and PCR products were purified by agarose gel electrophoresis using the GenCatch advanced PCR extraction kit (Epoch Life Science, Sugar Land, TX). Following restriction digestion and purification, linear plasmids and amplicons were ligated to generate recombinant plasmids. A $10-\mu \mathrm{L}$ ligation reaction (insert: vector ratio of 10:1) consisted of $10 \times \mathrm{T} 4$ ligase buffer $(1 \mu \mathrm{L})$, linearized plasmid and insert (0.02-0.5 pmol), T4 DNA ligase $(0.5 \mu \mathrm{L}$; New England Biolabs, Ipswich, MA), and nuclease-free water. The ligation reaction was incubated overnight at $16{ }^{\circ} \mathrm{C}$, and then heat-inactivated at $65^{\circ} \mathrm{C}$ for $10 \mathrm{~min}$, and chilled on ice.

\section{Transformation of $E$. coli DH5a and $C b$ with recombinant plasmids}

Electro-transformation of E. coli $\mathrm{DH} 5 \alpha$ was conducted according to standard protocols. Colonies were selected on LB agar plate supplemented with ampicillin $(50 \mu \mathrm{g} /$ $\mathrm{mL})$. Following isolation of recombinant plasmids from E. coli $\mathrm{DH} 5 \alpha$, the presence of desired inserts was verified by PCR, restriction digestion analysis, and DNA sequencing (Eurofins genomics, Louisville, KY).

To prepare electro-competent $C b$ cells, spores suspension $(200 \mu \mathrm{L})$ was heat-shocked as previously described $[22,30]$. $C b$ culture was then grown according to the previously described protocol [30]. The culture was then plated onto semi-solid TGY agar $[0.5 \%(\mathrm{w} / \mathrm{v})]$ and incubated until single colonies appeared. A single colony was inoculated into $10-\mathrm{mL}$ TGY broth and incubated for $10-12 \mathrm{~h}$. After $12 \mathrm{~h}$, the actively growing $\mathrm{Cb}$ culture $(10 \%, v / v)$ was then transferred into a fresh TGY broth and incubated until $\mathrm{OD}_{600}$ reached 0.6-0.8. Cells were harvested by spinning at $4000 \times g$ and $4{ }^{\circ} \mathrm{C}$ for $6 \mathrm{~min}$. Cell pellets were washed once with electroporation buffer $(50 \mathrm{~mL})$ containing $270 \mathrm{mM}$ sucrose, $1 \mathrm{mM} \mathrm{MgCl} 2,5 \mathrm{mM}$ $\mathrm{KH}_{2} \mathrm{PO}_{4}$, and $10 \% \mathrm{w} / \mathrm{v}$ PEG-8000. Electro-competent $\mathrm{Cb}$ cells were re-suspended in $2 \mathrm{~mL}$ of the electroporation buffer and incubated on ice for $5 \mathrm{~min}$.
To transform $C b, 10 \mu \mathrm{g}$ of recombinant plasmid was gently mixed with $400 \mu \mathrm{L}$ of the freshly prepared electrocompetent $\mathrm{Cb}$ in a pre-chilled $0.2-\mathrm{cm}$ electroporation cuvette. Electroporation was performed at $2.5 \mathrm{kV}, 25 \mu \mathrm{F}$ capacitance, and infinite resistance in a Bio-Rad Gene Pulser $\mathrm{Xcell}^{\mathrm{TM}}$ electroporator [32]. After electroporation, cells were diluted in $4 \mathrm{~mL}$ of TGY medium and incubated anaerobically at $35{ }^{\circ} \mathrm{C}$ for $6 \mathrm{~h}$. The resulting cells were pelleted by centrifugation at $3000 \times g$ for $5 \mathrm{~min}$ and then mixed with $30-\mathrm{mL}$ semi-solid TGY agar containing $25 \mu \mathrm{g} /$ $\mathrm{mL}$ erythromycin, poured into two separate petri dishes and incubated in an anaerobic chamber for 48-72 h. Subsequently, colonies were selected, transferred onto fresh semi-solid TGY agar containing $25 \mu \mathrm{g} / \mathrm{mL}$ erythromycin), and grown for another $12-24 \mathrm{~h}$. Then, colonies from each transformant were transferred into culture tubes containing TGY broth supplemented with $25 \mu \mathrm{g} / \mathrm{mL}$ erythromycin. The presence of the desired inserts was verified by PCR, restriction digestion analysis, and DNA sequencing (Eurofins genomics, Louisville, KY).

To prepare routine laboratory stocks of $C b$ transformants, $6 \%(\mathrm{v} / \mathrm{v})$ actively growing cells were inoculated into TGY broth containing $50 \mathrm{~g} / \mathrm{L}$ glucose supplemented with erythromycin $(25 \mu \mathrm{g} / \mathrm{mL})$ supplementation, and then grown for 7-8 days to allow for complete sporulation of the cells. At the end of fermentation, spores were harvested by centrifugation at $3000 \times g$ and $4{ }^{\circ} \mathrm{C}$ for $15 \mathrm{~min}$. The pellets were washed 5-8 times with sterile distilled water, and then suspended in sterile distilled water, and stored at $4{ }^{\circ} \mathrm{C}$.

\section{Batch fermentation to evaluate butanol production, glycerol utilization, and the furfural tolerance of recombinant $\mathrm{Cb}$ strains}

Spores $(200 \mu \mathrm{L})$ of recombinant $C b$ strains were heatshocked and inoculated into TGY broth supplemented with $25 \mu \mathrm{g} / \mathrm{mL}$ erythromycin as previously described $[22,30] . C b$ pre-culture was prepared according to the method of Ezeji et al. [33] using actively growing $\mathrm{Cb}$ cultures grown in TGY broth containing $25 \mu \mathrm{g} / \mathrm{mL}$ erythromycin. Butanol fermentation was conducted in loosely capped $50-\mathrm{mL}$ Pyrex culture bottles using $6 \%(\mathrm{v} / \mathrm{v})$ of the pre-culture in $50 \mathrm{~mL}$ of modified P2 medium [33] supplemented with $20 \mu \mathrm{g} / \mathrm{mL}$ erythromycin. The carbon source in the P2 medium was modified as follows: (i) glucose + glycerol (1:2 molar ratio; $36 \mathrm{~g} / \mathrm{L}$ glucose and $36.1 \mathrm{~g} / \mathrm{L}$ glycerol, respectively), (ii) glucoseonly $(60 \mathrm{~g} / \mathrm{L})$, and (iii) glucose + glycerol [1:2 molar ratio as in (i) above, with furfural supplementation $(2,3,4,5$, and $6 \mathrm{~g} / \mathrm{L})]$. For furfural-supplemented cultures (iii above), at $10-12 \mathrm{~h}\left(\mathrm{OD}_{600}\right.$ of 0.9$)$, the cultures were pulse-fed with furfural to the stated final concentrations. All experiments were performed in triplicate. During the course of fermentation, sample aliquots 
(2 mL) were taken at every 6- to 12-h intervals for analysis of cell growth, culture $\mathrm{pH}$, and the concentrations of butanol, acetone, ethanol, acetic and butyric acids, glucose and glycerol, furfural, and furfuryl alcohol (see analytical methods section for details).

\section{Glycerol dehydrogenase assay}

The activity of recombinant Gldh was determined as previously described by measuring the reduction of a colorless tetrazolium salt to purple formazan [34, 35]. Recombinant cells growing at mid-exponential phase $(16 \mathrm{~h})$ and midstationary phase (36 and $48 \mathrm{~h}$ ) were harvested and washed with $100 \mathrm{mM} \mathrm{KHCO}_{3}$ buffer. Cell pellets were lysed in a Qiagen Tissue Lyser LT (Qiagen, Hilden, Germany) at 50 oscillations/s for $3 \mathrm{~min}$, with addition of $0.1-\mathrm{mm}$-diameter zirconia/silica beads (BioSpec, Bartlesville, OK). Cell debris was removed by centrifuging the mixture at $10,000 \times g$ and $4{ }^{\circ} \mathrm{C}$ for $5 \mathrm{~min}$. A $300-\mu \mathrm{L}$ reaction mixture consisting $100 \mathrm{mM} \mathrm{KHCO}_{3}(\mathrm{pH} 9.5), 250 \mu \mathrm{g} / \mathrm{mL}$ gelatin, $100 \mathrm{mM}$ glycerol, $1 \mathrm{mM} \mathrm{NAD}{ }^{+}, 1 \mathrm{mM} 2-p$-iodo-3- $p$ nitrophenyl-5-phenyl-2H-tetrazolium chloride (INT), and $0.065 \mathrm{mM}$ phenazine methosulfate (PMS) was prepared. The reaction mixture and the quartz cuvette used for the assay were pre-incubated at $37^{\circ} \mathrm{C}$ in a water bath and a DU ${ }^{\circledR} 800$ spectrophotometer (Beckman Coulter Inc., Brea, CA), respectively. To start the reaction, $100-\mu \mathrm{L}$ crude cell extract was added to $300 \mu \mathrm{L}$ of pre-warmed reaction mixture in a cuvette. Absorbance $(580 \mathrm{~nm})$ was measured every $1 \mathrm{~min}$ for $20 \mathrm{~min}$ and then subtracted from those of the control (blank) consisting of $100-\mu \mathrm{L}$ sterile distilled water and $300-\mu \mathrm{L}$ reaction mixture.

A graph of absorbance versus time was plotted and the initial velocity (mM INT formazan formed/min) was determined according to a previously described protocol, using the extinction coefficient of formazan $\left(12,300 / \mathrm{M}^{\prime} \mathrm{cm}\right.$ @ $580 \mathrm{~nm}$; $[36,37]$ and pathlength $(1 \mathrm{~cm})$. Protein concentration was estimated according to the method described by Bradford [38] using a commercial reagent (Amresco, Solon, $\mathrm{OH}$ ). Bovine serum albumin was used as a standard. One unit of specific enzyme activity was defined as $\mu$ mol INT formazan formed per min per mg protein.

\section{Dihydroxyacetone kinase assay}

The activity of DhaK was determined in a coupled assay with glycerol-3-phosphate dehydrogenase by monitoring the rate of ATP-dependent oxidation of NADH to $\mathrm{NAD}^{+}$monitored at $340 \mathrm{~nm}$ [39]. In the coupled assay, DHAP (the product of ATP-dependent DhaK reaction) is reduced to glycerol-3-phosphate by NADHdependent glycerol-3-phosphate dehydrogenase. $C b$ cells growing to mid-exponential and stationary phases in glycerol-supplemented P2 medium were harvested and washed with $10 \mathrm{~mL}$ of ice-cold $20 \mathrm{mM}$ 2-(N-morpholino)ethanesulfonic acid buffer (MES; pH 6.5). The cell pellet was lysed in a Qiagen Tissue Lyser LT (Qiagen, Hilden, Germany) at 50 oscillations/s for $3 \mathrm{~min}$. A $350-\mu \mathrm{L}$ reaction mixture, which consisted of $5 \mu \mathrm{g} / \mathrm{mL}$ $\alpha$-glycerophosphate dehydrogenase, $20 \mathrm{mM} \mathrm{MgCl}_{2}$, $10 \mathrm{mM}$ 2,2-dipyridyl, $1 \mathrm{mM} \mathrm{KCN}, 0.1 \mathrm{M}$ imidazole (pH 7.5), 2 mM MES ( $\mathrm{pH}$ 6.5), $4 \mathrm{mM}$ dihydroxyacetone, $10 \mathrm{mM}$ ATP, and $0.1 \mathrm{mM} \mathrm{NADH}$ was prepared. The reaction mixture and quartz cuvettes used for the assay were pre-incubated at $30{ }^{\circ} \mathrm{C}$ for $5 \mathrm{~min}$ in a water bath and a DU ${ }^{\circledR} 800$ spectrophotometer (Beckman Coulter Inc., Brea, CA), respectively. To start the reaction, $50-\mu \mathrm{L}$ crude $C b$ cell-free extract was added to $350 \mu \mathrm{L}$ of pre-warmed reaction mixture. Absorbance $(340 \mathrm{~nm})$ was measured every 2 to $5 \mathrm{~min}$ for $40 \mathrm{~min}$ and then subtracted from those of the control blank $(50-\mu \mathrm{L}$ sterile distilled water and $350-\mu \mathrm{L}$ reaction mixture).

The activity of DhaK was calculated based on the extinction coefficient of NADH (6220/M/cm @ 340 nm; [40]) and path length $(1 \mathrm{~cm})$. Protein concentration was estimated as described above (glycerol dehydrogenase assay). One unit of specific DhaK activity was defined as the $\mu \mathrm{mol} \mathrm{NADH}$ oxidized per min per mg protein.

\section{Analytical methods}

Cell growth was determined by measuring optical density at $600 \mathrm{~nm}\left(\mathrm{OD}_{600}\right)$ using a $\mathrm{DU}^{\circledR} 800$ spectrophotometer (Beckman Coulter Inc., Brea, CA). Changes in the concentrations of furfural and furfuryl alcohol were determined by monitoring changes in wavelength using a DU ${ }^{\circledR} 800$ spectrophotometer. The maximum absorption spectra of furfural and furfuryl alcohol are at 275 and $220 \mathrm{~nm}$, respectively. Furfural and furfuryl alcohol concentrations were further validated by High Performance Liquid Chromatography (HPLC) using a Waters 2796 Bioseparation Module equipped with Photodiode Array Detector (PDA; Waters, Milford, MA) and a 3.5$\mu \mathrm{m}$ Xbridge C18, $150 \mathrm{~mm} \times 4.6 \mathrm{~mm}$ column (Waters, Milford, MA). Samples were eluted using a gradient mobile phase of acetic acid [0.3\% (v/v) in HPLC-grade water] and HPLC-grade methanol, operated at a flow rate of $0.6 \mathrm{~mL} / \mathrm{min}$ as previously described [10].

Glycerol concentration was quantified by HPLC using the Waters 2796 Bioseparations Module equipped with a photodiode array (PDA) detector (Waters, Milford, MA), and a Prevail $^{\mathrm{TM}}$ Carbohydrates ES Column-W $250 \mathrm{~mm} \times 4.6 \mathrm{~mm} \times 5 \mu \mathrm{m}$ column (Grace Davison Discovery Science, Deerfiled, IL) maintained at $30{ }^{\circ} \mathrm{C}$ in series with an All-Guard ${ }^{\mathrm{TM}}$ Cartridge System (Alltech Associates Inc., Deerfield, IL). The mobile phase was acetonitrile $[78 \%(\mathrm{v} / \mathrm{v})]$ and water $[22 \%(\mathrm{v} / \mathrm{v})]$ at a flow rate of $1 \mathrm{~mL} / \mathrm{min}$ and isocratic pump mode. Sample temperature and 
injection volume were $25{ }^{\circ} \mathrm{C}$ and $10 \mu \mathrm{L}$, respectively. Glucose concentrations were quantified using the 3,5-dinitrosalicylic acid (DNS) method [41]. Determination of glucose concentration was performed using a Waters 2796 Bioseparation module equipped with Evaporative Light Scattering Detector (ELSD; Waters, Milford, MA) and a 9- $\mu \mathrm{m}$ Aminex HPX-87P, $300 \mathrm{~mm} \times 7.8 \mathrm{~mm}$ column maintained at $65^{\circ} \mathrm{C}$ in series with an Aminex deashing guard column (4.6 mm internal diameter $\times 3 \mathrm{~cm}$ long; Bio-Rad, Hercules, $\mathrm{CA}$ ). The mobile phase was HPLC-grade water at a flow rate of $0.6 \mathrm{~mL} / \mathrm{min}$ [13].

The concentrations of acetone, butanol, ethanol, acetic acid, and butyric acid, were determined using a 7890A Agilent gas chromatograph (Agilent Technologies Inc., Wilmington, $\mathrm{DE}$ ) equipped with a flame ionization detector (FID) and $30 \mathrm{~m}$ (length) $\times 320 \mu \mathrm{m}$ (internal diameter $\times 0.50 \mu \mathrm{m}($ HP-INNOWax film) $\mathrm{J} \times \mathrm{W} 19091 \mathrm{~N}-213$ capillary column as described previously Agu et al. [10]. $\mathrm{ABE}$ yield was defined as total $\mathrm{ABE}$ produced (in grams) per grams of glucose (or glucose + glycerol) utilized. Productivity was calculated as the concentration $(\mathrm{g} / \mathrm{L})$ of $\mathrm{ABE}$ produced per hour.

\section{Statistical analysis}

The General Linear Model of Minitab version 17 (Minitab Inc., State College, PA) was used for all statistical analyses to compare differences between treatments. Differences in growth, product yields and productivities, rate of furfural reduction, and the concentrations of sugars, furfural and furfuryl alcohol, acetone, butanol, ethanol, and ABE were compared. ANOVA was conducted at different fermentation time points. Fisher's least significant difference at $90 \%$ confidence interval was applied to pair-wise comparison to separate means.

\section{Additional file}

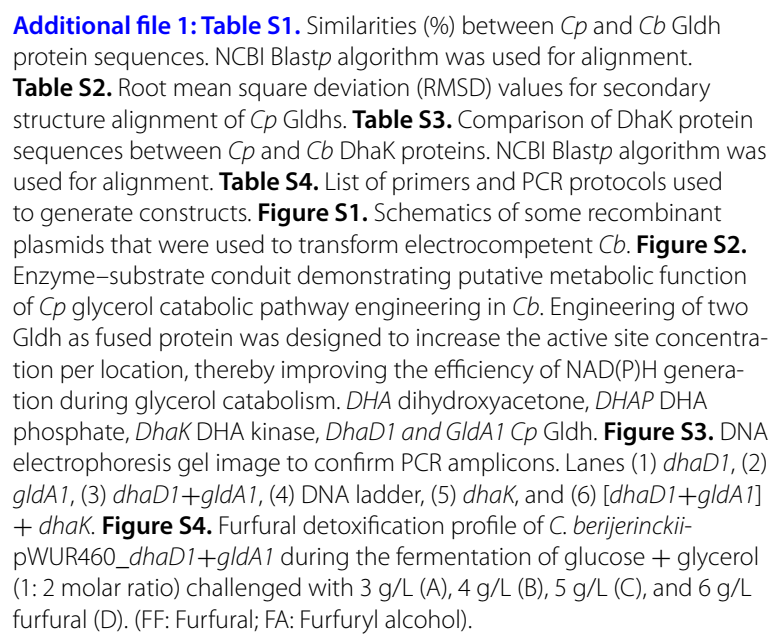

\section{Authors' contributions}

CVA performed the experiments and analyzed the data; TCE conceived the experiments; VU and TCE designed the experiments. CVA and VU wrote the manuscript. All authors contributed to the revision of the manuscript. All authors read and approved the final manuscript.

\section{Author details \\ ${ }^{1}$ Department of Animal Sciences and Ohio State Agricultural Research and Development Center (OARDC), The Ohio State University, 305 Gerlaugh Hall, 1680 Madison Avenue, Wooster, OH 44691, USA. ${ }^{2}$ INanoBio Inc., 320 Logue Ave., Suite 212, Mountain View, CA 94043, USA. ${ }^{3}$ Bioenergy and Biologi- cal Waste Management Program, Agricultural Technical Institute, The Ohio State University, 1328 Dover Road, Wooster, OH 44691, USA.}

\section{Acknowledgements}

We thank Dr. Wouter Kuit (Wageningen University and Research Centre, Wageningen, Netherlands) for kindly providing us pWUR459 and pWUR460 expression plasmids. We would also like to thank Drs. Venkat Gopalan and Lien Lai for hosting C.V.A briefly in their laboratory and for valuable discussions.

\section{Competing interests}

The authors declare that they have no competing interests.

\section{Availability of data and materials}

All data generated or analyzed during this study are included in this published article (and its additional file). Any other data related to this manuscript will be made available by the corresponding author upon reasonable request.

\section{Consent for publication}

Not applicable.

Ethics approval and consent to participate Not applicable.

\section{Funding}

Funding for this research was provided in part by the USDA NIFA Hatch grant (Project No. OHO01333), National Science Foundation, and by state funds allocated to the Ohio Agricultural Research and Development Center (OARDC).

\section{Publisher's Note}

Springer Nature remains neutral with regard to jurisdictional claims in published maps and institutional affiliations.

Received: 6 July 2018 Accepted: 25 February 2019

Published online: 09 March 2019

\section{References}

1. U.S. Department of Energy (2011) U.S. billion-ton update. Biomass supply for a bioenergy and bioproducts industry. www1.eere.energy.gov/bioen ergy/pdfs/billion_ton_update.pdf. Accessed 15 June 2016.

2. U.S. Energy Information Administration (2018) Monthly Biodiesel Production Report. https://www.eia.gov/biofuels/biodiesel/production/. Jan 2018.

3. Johnson DT, Taconi KA. The glycerin glut: options for the value-added conversion of crude glycerol resulting from biodiesel production. Environ Prog. 2007;26(4):338-48.

4. Saint-Amans S, Girbal L, Andrade J, Ahrens K, Soucaille P. Regulation and electron flow in Clostridium butyricum VPI 3266 grown on glucoseglycerol mixtures. J Bacteriol. 2001;183:1748-53.

5. Raynaud C, Sarcabal P, Meynial-Salles I, Croux C, Soucaille P. Molecular characterization of the 1,3-Propanediol (1,3-PD) operon of Clostridium butyricum. Appl Biol Sci. 2003;100:5010-5.

6. Neijssel OM, Hueting S, Crabbendam KJ, Tempest DW. Dual pathways of glycerol assimilation in Klebsiella aerogenes NCIMB 418. Arch Microbiol. 1975;104:83-7.

7. Lin ECC. Glycerol dissimilation and its regulation in bacteria. Ann Rev Microbiol. 1976;30:535-78. 
8. Eggersdorfer M, Meyer J, Eckes P. Use of renewable resources for nonfood materials. FEMS Microbiol Rev. 1992;103:355-64.

9. Taconi KA, Venkataramanan KP, Johnson DT. Growth and solvent production by Clostridium pasteurianum ATCC 6013 utilizing biodiesel-derived crude glycerol as the sole carbon source. Environ Prog Sustain Energy. 2009;28(1):100-10.

10. Agu CV, Ujor V, Gopalan V, Ezeji TC. Use of Cupriavidus basilensis-aided bioabatement to enhance fermentation of acid-pretreated biomass hydrolysates by Clostridium beijerinckii. J Ind Microbiol Biotechnol. 2016;43(9):1215-26.

11. Agu CV, Ujor V, Ezeji TC. Allopurinol supplementation of the growth medium enhances the fermentation of lignocellulosic hydrolysates to ethanol by Saccharomyces cerevisiae. Biocat Agric Biotechnol. 2018;14:151-9.

12. Zhang Y, Ezeji TC. Elucidating and alleviating impacts of lignocellulosederived microbial inhibitors on Clostridium beijerinckii during fermentation of Miscanthus giganteus to butanol. J Ind Microbiol Biotechnol. 2014:41(10):1505-16.

13. Ujor V, Agu CV, Gopalan V, Ezeji TC. Glycerol supplementation of the growth medium enhances in situ detoxification of furfural by Clostridium beijerinckii during butanol fermentation. Appl Microbiol Biotechnol. 2014;98(14):6511-21.

14. Girbal L, Soucaille P. Regulation of Clostridium acetobutylicum metabolism as revealed by mixed-substrate steady-state continuous cultures: role of NADH/NAD ratio and ATP pool. J Bacteriol. 1994;176(21):6433-8.

15. Vasconcelos I, Girbal L, Soucaille P. Regulation of carbon and electron flow in Clostridium acetobutylicum grown in chemostat culture at neutral pH on mixtures of glucose and glycerol. J Bacteriol. 1994;176(5):1443-50.

16. Liyanage H, Young M, Kashket ER. Butanol tolerance of Clostridium beijerinckii NCIMB 8052 associated with down-regulation of gldA by antisense RNA. J Mol Microbiol Biotechnol. 2000:2(1):87-93.

17. Dabrock B, Bahl H, Gottschalk G. Parameters affecting solvent production by Clostridium pasteurianum. Appl Environ Microbiol. 1992;58(4):1233.

18. Venkataramanan KP, Kurniawan Y, Boatman JJ, Haynes $\mathrm{CH}$, Taconic KA, Martin L, et al. Homeoviscous response of Clostridium pasteurianum to butanol toxicity during glycerol fermentation. J Biotech. 2014;179:8-14.

19. Sabra W, Groeger C, Sharma PN, Zeng A. Improved n-butanol production by a non-acetone producing Clostridium pasteurianum DSMZ 525 in mixed substrate fermentation. Appl Microbiol Biotechnol. 2014:98:4267-76

20. Richmond C, Ujor V, Ezeji TC. Impact of syringaldehyde on the growth of Clostridium beijerinckii NCIMB 8052 and butanol production. 3 Biotech. 2012;2(2):159-67.

21. Zhang Y, Han B, Ezeji TC. Biotransformation of furfural and 5-hydroxymethyl furfural (HMF) by Clostridium acetobutylicum ATCC 824 during butanol fermentation. New Biotechnol. 2012;29(3):345-51.

22. Ujor V, Agu CV, Gopalan V, Ezeji TC. Allopurinol-mediated lignocellulosederived microbial inhibitor tolerance by Clostridium beijerinckii during acetone-butanol-ethanol (ABE) fermentation. Appl Microbiol Biotechnol. 2015;99(8):3729-40

23. Huffer S, Clark ME, Ning JC, Blanch HW, Clark DS. Role of alcohols in growth, lipid composition, and membrane fluidity of yeasts, bacteria, and archaea. Appl Microbiol Biotechnol. 2011;77(18):6400-8.

24. Dueber JE, Wu GC, Malmirchegini GR, Moon TS, Petzold CJ, Ullal AV, et al. Synthetic protein scaffolds provide modular control over metabolic flux. Nat Biotechnol. 2009;27(8):753-61.
25. Siemerink MAJ, Kuit W, Lopez-Contreras AM, Eggink G, van der Oost JV, Kengen SWM. D-2,3-Butanediol production due to heterologous expression of an acetoin reductase in Clostridium acetobutylicum. Appl Environ Microbiol. 2011;77(8):2582-8.

26. Girbal L, Mortier-Barrière I, Raynaud F, Rouanet C, Croux C, Soucaille P. Development of a sensitive gene expression reporter system and an inducible promoter-repressor system for Clostridium acetobutylicum. Appl Environ Microbiol. 2003;69:4985-8

27. Nguyen N-PT, Linder S, Flitsch SK, Schiel-Bengelsdorf B, Dürre P, Soucaille P. Cap0037, a novel global regulator of Clostridium acetobutylicum metabolism. mBio. 2016;7:e01218-316. https://doi.org/10.1128/mbio.01218-16.

28. Gonzalez-Pajuelo M, Meynial-Salles I, Mendes F, Soucaille P, Vasconcelos I. Microbial conversion of glycerol to 1,3-propanediol: physiological comparison of a natural producer, Clostridium butyricum VPI 3266, and an engineered strain, Clostridium acetobutylicum DG1 (PSPD5). Appl Environ Microbiol. 2006;72(1):96-101.

29. Almeida JRM, Röder A, Modig T, Laadan B, Lidén G, Gorwa-Grauslund MF. $\mathrm{NADH}$ - vs NADPH-coupled reduction of 5-hydroxymethyl furfural (HMF) and its implications on product distribution in Saccharomyces cerevisiae. Appl Microbiol Biotechnol. 2008;78:939-45.

30. Agu CV, Lai SM, Ujor V, Biswas PK, Jones A, Gopalan V, Ezeji TC. Development of a high-throughput assay for rapid screening of butanologenic strains. Sci Rep. 2008;8:3379.

31. Horton RM, Hunt HD, Ho SN, Pullen JK, Pease LR. Engineering hybrid genes without the use of restriction enzymes: gene splicing by overlap extension. Gene. 1989;77:61-8.

32. Zhou Y, Johnson EA. Genetic transformation of Clostridium botulinum by electroporation. Biotechnol Lett. 1993;15:121-6.

33. Ezeji TC, Qureshi N, Blaschek HP. Production of butanol by Clostridium beijerinckii BA101 and in situ recovery by gas stripping. World J Microbiol Biotechnol. 2003;19:595-603.

34. Nachlas MM, Margulies SI, Goldberg JD, Seligman AM. Determination of lactic dehydrogenase with a tetrazolium salt. Anal Biochem. 1960;1:317-26

35. Ruch FE, Lengeler J, Lin ECC. Regulation of glycerol catabolism in Klebsiella aerogenes. J Bacteriol. 1974;119:50-6.

36. Fibla J, Gonzàlez-Duarte R. Colorimetric assay to determine alcohol dehydrogenase activity. J Biochem Biophys Methods. 1993;26:87-93.

37. Srivastava AK, Srivastava S, Lokhande VH, D'Souza SF, Suprasanna P. Salt stress reveals differential antioxidant and energetics responses in glycophyte (Brassica juncea L.) and halophyte (Sesuvium portulacastrum L.). Front Environ Sci. 2015:3(19):1-9.

38. Bradford MM. A rapid and sensitive method for the quantitation of microgram quantities of protein utilizing the principle of protein-dye binding. Anal Biochem. 1976;72:248-54.

39. Gancedo C, Llobell A, Ribas JC, Luchi F. Isolation and characterization of mutants from Schyzosaccharornyces pombe defective in glycerol catabolism. Eur J Biochem. 1986;159:171-4.

40. Swetha VP, Basu A, Phale PS. Purification and characterization of 1-naphthol-2-hydroxylase from carbaryl-degrading Pseudomonas strain C4. J Bacteriol. 2007:189(7):2660-6.

41. Miller GL. Use of dinitrosalicylic acid reagent for determination of reducing sugar. Anal Chem. 1959;31(3):426-8.

Ready to submit your research? Choose BMC and benefit from

- fast, convenient online submission

- thorough peer review by experienced researchers in your field

- rapid publication on acceptance

- support for research data, including large and complex data types

- gold Open Access which fosters wider collaboration and increased citations

- maximum visibility for your research: over 100M website views per year

At BMC, research is always in progress.

Learn more biomedcentral.com/submissions 